\title{
Recent trends in biogas value chains explained using cooperative game theory
}

\author{
Skovsgaard, Lise; Jensen, Ida Græsted
}

Published in:

Energy Economics

Link to article, DOI:

10.1016/j.eneco.2018.06.021

Publication date:

2018

Document Version

Peer reviewed version

Link back to DTU Orbit

Citation (APA):

Skovsgaard, L., \& Jensen, I. G. (2018). Recent trends in biogas value chains explained using cooperative game theory. Energy Economics, 74, 503-522. https://doi.org/10.1016/j.eneco.2018.06.021

\section{General rights}

Copyright and moral rights for the publications made accessible in the public portal are retained by the authors and/or other copyright owners and it is a condition of accessing publications that users recognise and abide by the legal requirements associated with these rights.

- Users may download and print one copy of any publication from the public portal for the purpose of private study or research.

- You may not further distribute the material or use it for any profit-making activity or commercial gain

- You may freely distribute the URL identifying the publication in the public portal

If you believe that this document breaches copyright please contact us providing details, and we will remove access to the work immediately and investigate your claim 


\section{Accepted Manuscript}

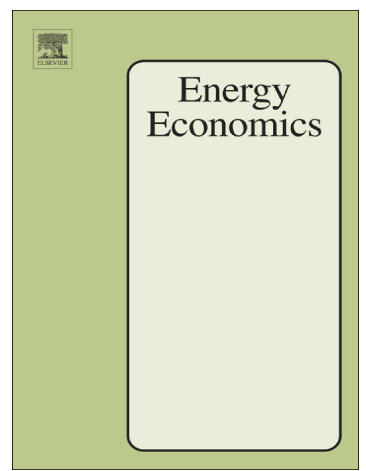

Lise Skovsgaard, Ida Græsted Jensen

PII: $\quad$ S0140-9883(18)30239-1

DOI: $\quad$ doi:10.1016/j.eneco.2018.06.021

Reference: $\quad$ ENEECO 4072

To appear in: $\quad$ Energy Economics

Received date: $\quad 23$ June 2017

Revised date: $\quad$ 19 June 2018

Accepted date: $\quad 27$ June 2018

Please cite this article as: Lise Skovsgaard, Ida Græsted Jensen, Recent trends in biogas value chains explained using cooperative game theory. Eneeco (2018), doi:10.1016/ j.eneco.2018.06.021

This is a PDF file of an unedited manuscript that has been accepted for publication. As a service to our customers we are providing this early version of the manuscript. The manuscript will undergo copyediting, typesetting, and review of the resulting proof before it is published in its final form. Please note that during the production process errors may be discovered which could affect the content, and all legal disclaimers that apply to the journal pertain. 


\title{
Recent trends in biogas value chains explained using cooperative game theory
}

\author{
Lise Skovsgaard ${ }^{\mathrm{a}, *}$, Ida Græsted Jensen ${ }^{\mathrm{a}}$ \\ ${ }^{a}$ Technical University of Denmark, DTU Management Engineering, Produktionstorvet, Building 426, 2800 Kongens \\ Lyngby, Denmark
}

\begin{abstract}
In Denmark, since 2014, it has been possible to upgrade biogas to a gas grid and achieve support in line with biogas-based heat and power production. Since then, most new biogas production plants have chosen to upgrade their biogas. In this study, a mixed integer programming model is used to find the optimal biogas value chain, and cooperative game theory is used to understand real world observations compared to this study's results. Specifically, three profit allocation mechanisms are applied to allocate the profit between the heterogeneous owners in the value chain. It is found that Danish biogas plants should use large shares of manure combined with deep litter. Furthermore, it is found that input suppliers have relatively poor bargaining power in the profit allocation negotiations due to poor alternatives. This may explain why livestock farmers tend to receive little payment for their manure, and why they are hesitant to join biogas projects.

Finally, it is found that biogas plants prefer to upgrade their biogas for several reasons. First, if the natural gas price is expected to be high, it is preferable to upgrade biogas than to use it directly in a local combined heat and power plant (CHP). Second, if the natural gas price is expected to be low, it is preferable to upgrade because the CHPs have better alternatives and therefore better bargaining power before investments (ex ante). Third, when the value chain contains an upgrading plant, the biogas plant has a greater bargaining power -in particular ex post.
\end{abstract}

Keywords: Cooperative game theory, Profit allocation, Mixed integer programming, Biogas, Biomethane, Value chain

\section{Introduction}

Danish biogas production has developed remarkably recently since a change in regulation following the Energy Agreement in 2012 (Danish Government, 2012), where it was agreed that biogas, among other renewable energy sources, should be strengthened economically. Thus, several initiatives began. The probably most important initiative was that, after an EU ratification in 2014, it

\footnotetext{
${ }^{*}$ Corresponding author: lskn@dtu.dk
} 
became possible to gain support when biogas is upgraded for the gas grid, used directly for industry or transport, or used directly for heat and power production (Danish Energy Association, 2013; European Commision, 2013). The new initiatives have been successful, and new biogas plants have been built throughout Denmark the latest years (Harder, 2016). Moreover, biogas upgrading has increased the possibility to take advantage of economies of scale independent of local heat demands (Skovsgaard and Jacobsen, 2017).

Considering these latest developments, as well as projections for new biogas plants, it is clear that there is a trend in which biogas plants often choose to upgrade theor biogas instead of finding local sources for biogas consumption. This development is in relation to not only new biogas plants but also existing biogas plants have chosen to upgrade their biogas and not proceed to deliver biogas to local CHPs (Harder, 2016). An explanation for this development could be a lack of heat demand, or at least a reduced heat demand, along with new, cheaper heat production technologies. However, two other possible explanations are investigated in this paper. The first is that an assumption on higher natural gas prices in the future yields higher expected profits for value chains in which biogas is upgraded than value chains in which biogas is used directly to produce heat and power. The second is that strategic considerations regarding potential profit allocations among members of the value chain after investments (ex post) can affect ex ante investment choices.

The biogas value chain involves several actors from different sectors that operate in diverse markets with diverse regulation. Moreover, the input for biogas production is typically a biproduct for the farmers, and biogas is one possible fuel out of many for the production of energy commodities. These factors may affect opportunities for biogas producers, the optimal pricing between the different actors in the value chain, and the optimal production decision. Additionally, both input and output prices can be difficult to estimate as there are no or imperfect markets for both inputs and output. These issues can be a challenge when profits should be allocated within the value chain.

Furthermore, parts of the biogas value chain can be considered bilateral monopolies after investments; these ex post consequences can affect investments in the value chain ex ante; such effects are discussed in this paper. The Myerson-Satterthwaite theorem (Myerson and Satterthwaite, 1983) states that in cases of private information, it is impossible to achieve ex post efficiency in bilateral trade; each time two owners meet, there is a risk of adverse selection with an inappropriate design of profit allocation mechanism. A solution to this challenge is vertical integration (Swami and Shah, 2011; Buzzell, 1983), of which there are several examples in biogas value chains; however, this solution is not always feasible.

Blair et al. (1989) finds a disagreement in the literature with regard to finding an optimal solution for quantity and price issues between bilateral monopolies. The researchers refer to Bowley (1928), Fellner (1947), and Machlup and Taber (1960) who found a joint profit maximising solution with a variety of assumptions. Blair et al. (1989) concluded that the social optimal solution can be found only with joint profit optimisation, and that a price between the parties is a way to share 
the maximised profit. Truett and Truett (1993) extended this and proved that under particular circumstances, hereunder perfect information, there is only one stable and theoretically optimal price for the intermediate products between two monopolies. This price depends, among other things, on the bargaining power between the two monopolies. Therefore, since vertical integration is not always an option, an alternative is to form a cooperative within which profits are maximised jointly, after which profits are allocated.

Within cooperative game theoretic literature, several allocation mechanisms have been presented and tested both theoretically, e.g. (Tijs, 1986; Schmeidler, 1969; Megiddo, 1978; McCain, 2008; Hougaard, 2009), and empirically, e.g. (Massol and Tchung-Ming, 2010; Frisk et al., 2010; Lozano et al., 2013; Nagarajan and Sošić, 2008). However, most literature is focused on homogeneous producer types with slightly different properties, where the cooperatives are alternatives to horizontal integration. Examples of this are a cooperative of pig producers who slaughter and sell the pigs together (Bogetoft and Olesen, 2007), a cooperative of liquefied natural gas suppliers (Massol and Tchung-Ming, 2010), and a cooperative of wood suppliers (Frisk et al., 2010). A typical allocation mechanism is proportional allocation with which profit is allocated: in accordance with cost (an equal return on capital) (Hougaard, 2009); in accordance with the marginal cost (alternate-costavoided) (Bogetoft and Olesen, 2007); or in accordance with the gain delivered to the cooperative (Shapley value) (Lemaire, 1984; Massol and Tchung-Ming, 2010; Frisk et al., 2010). Other payment schemes focus on the egalitarian principle, such as the egalitarian method, with which profit is divided equally between all parties in the cooperative (Tijs, 1986; Lemaire, 1984; Massol and Tchung-Ming, 2010), or the nucleolus payment scheme, with which profit allocation depends on the alternative profit of the marginal participant (Massol and Tchung-Ming, 2010; Schmeidler, 1969; Frisk et al., 2010).

In this paper, we apply some of these payment schemes to the non-homogeneous owners in the biogas value chain. Such application of cooperative game theory has been investigated theoretically, e.g. in (P. Cachon and Netessine, 2004), but to our knowledge, empirical applications are limited. In (Hubert and Ikonnikova, 2011) the bargaining power between Russia and central transit countries is compared for the Eurasian supply chain for natural gas. The study investigated several new investment options, including extensions of existing routes and entirely new transit routes. The bargaining power was evaluated by applying both the Shapley value and the nucleolus allocation mechanisms, the results of which were compared to empirical data on prices.

In this paper, we investigate the best value chain designs and analyse the empirical evidence for new investments in a game theoretic context. We apply a value chain optimisation model (Jensen et al., 2017) in order to determine the profits that might be gained under various energy price scenarios, assuming joint profit maximisation under perfect information; this is presented in Section 3. Applying the model, we find the optimal biogas value chain design including the optimal inputs and the optimal energy converter, given a specific set of assumptions; this result is presented in Section 5.1. Moreover, drawing on cooperative and non-cooperative game theory 
(McCain, 2008; Gibbons, 1992) and cost and profit allocation theory (Hougaard, 2009; Bogetoft and Olesen, 2007), we compare the results of three profit allocation mechanisms and discuss how ex post bargaining power may affect ex ante choices made by key owners through backward induction with regard to value chain design. We then argue that such effects can change the preferred design more than anticipated. We discuss this in Sections 5.2 and 5.4, based on the theory presented in Section 4. Finally, we present the policy implications in Section 6.

\section{Biogas production in Denmark}

The biogas value chain, see 1 , consists of several separate owners, who often operate in various markets in different sectors. In this paper, the group of owners comprises livestock farmers, substrate farmers, a biogas plant and energy converters. These parties deliver inputs and/or are involved directly in biogas production and conversion processes. However, only the plant, and in some cases the biogas upgrading facility, have biogas production as the primary purpose; the farmers focus on the highly competitive agricultural sector. The energy converter, at the end of the value chain, focuses on the end products of the chain: biomethane (upgraded biogas), electricity and/or heat. Heat production is considered a natural monopoly, and is therefore monopoly regulated, while electricity and gas markets are exposed to high levels of competition.

As Section 2.1 explains, the regulatory design implies that in order to be allowed to receive support, the biogas plant is dependent upon waste input (defined in this paper as agricultural waste) and in order to receive support, the biogas plant is dependent upon a demand from an energy converter. Both the agricultural and energy sectors are highly exposed to competition or monopoly regulated.

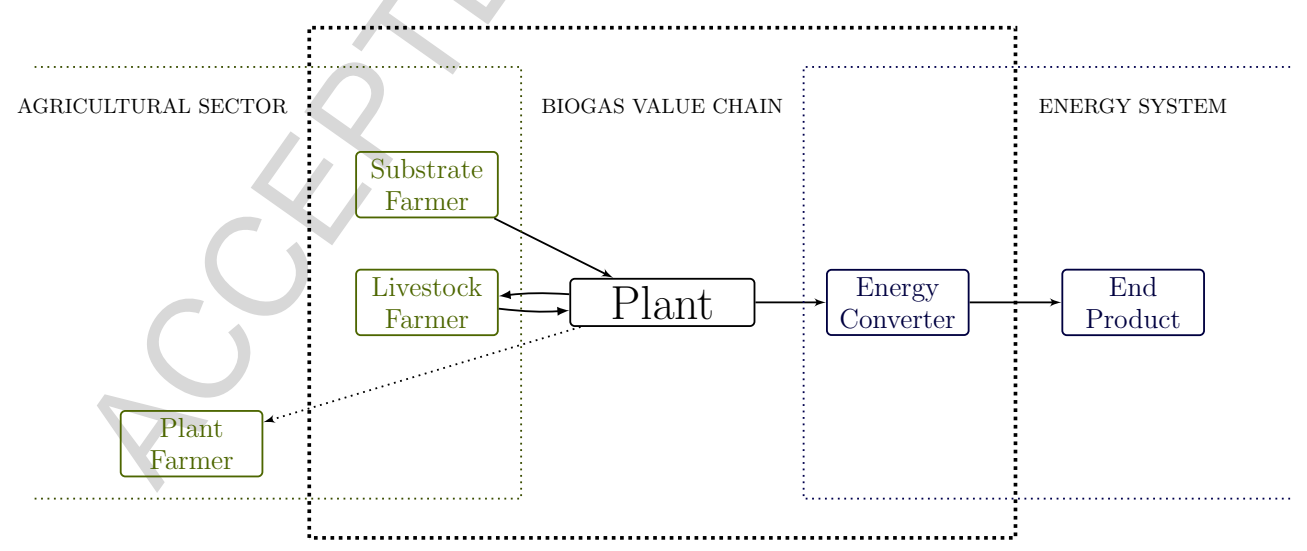

Figure 1: The biogas value chain and the ownership structure

The ownership structures of biogas value chains vary by plant, and in Denmark there are several variations. For example in one, a group of farmers invested in a biogas plant and an upgrading facility, i.e. Madsen Bioenergi (Madsen Bioenergi, 2017). In another, one owner controls inputs and biogas production, while another owner controls the upgrading plant, i.e. Fredericia Wastewater 
and Energy (Wittrup, 2010). This is because specific ownership structure choices depend on several factors; for example, heat and power plants are often restricted from investing in biogas plants as regulators often consider such investments as high risk. Moreover, some farmers have limited access to low interest rate capital as they have significant amounts of capital invested in their farms. A solution to these issues is to have both farmers and external investors, such as the energy companies E.ON, Nature Energy and Ørsted, as investors in biogas plants. It should be noted that some value chains are vertically integrated in ownership, while others are not; for value chains with limited integration, the strategic considerations with regard to profit allocation are particularly interesting.

\subsection{Regulation}

Danish biogas regulation spans several sectors and different priorities. Biogas support and the regulatory set-up are designed in an energy focused mindset, while at the same time considering the need of sustainability and, therefore, the need of using manure for biogas production. These are the focal points of the Danish biogas policy and they have a significant influence on the importance of each owner in the value chains. Two aspects of biogas regulation are presented in this section, and described in more detail in Appendix A:

- Input: In order to receive biogas support, a large share of the inputs for biogas production must consist of waste - preferably manure or waste water. Waste products from slaughterhouses and dairy production can also be used; however, these sources are limited. Moreover, biogas production can be supplemented with other waste products, such as straw and deep litter. Finally, limited amounts of energy crops may be used.

- Output: Biogas support is primarily given at the end of the value chain, i.e. to the energy converter. The energy converter can be an upgrading plant, a CHP, a heat producer, industry or transport.

The regulation regarding energy production and consumption is extensive in Denmark, where the general principles are that renewable energy is taxed as little as possible while electricity and fossil fuels are taxed heavily. Denmark and the surrounding countries have a highly competitive power market. Therefore, fuels used for electricity production are not taxed; rather, electricity consumption is taxed. Furthermore, if electricity is not used for processes, then consumption taxes and fees are limited - the highest fee being the Public Service Obligation (PSO), which will be phased out in 2022 (Danish Ministry of Energy, Utilities and Climate, 2016).

In contrast, gas is highly taxed and considered a rather expensive fuel. However, gas is a common fuel in decentral CHP production in Denmark, for which only gas used for the heat share of the production is taxed. Heat is not subject to competition in the same way as gas and power; instead, it is monopoly regulated.

Energy prices vary over time, and though electricity prices vary more than gas prices across day, month and years, gas prices can also change significantly, being for example twice as high in 


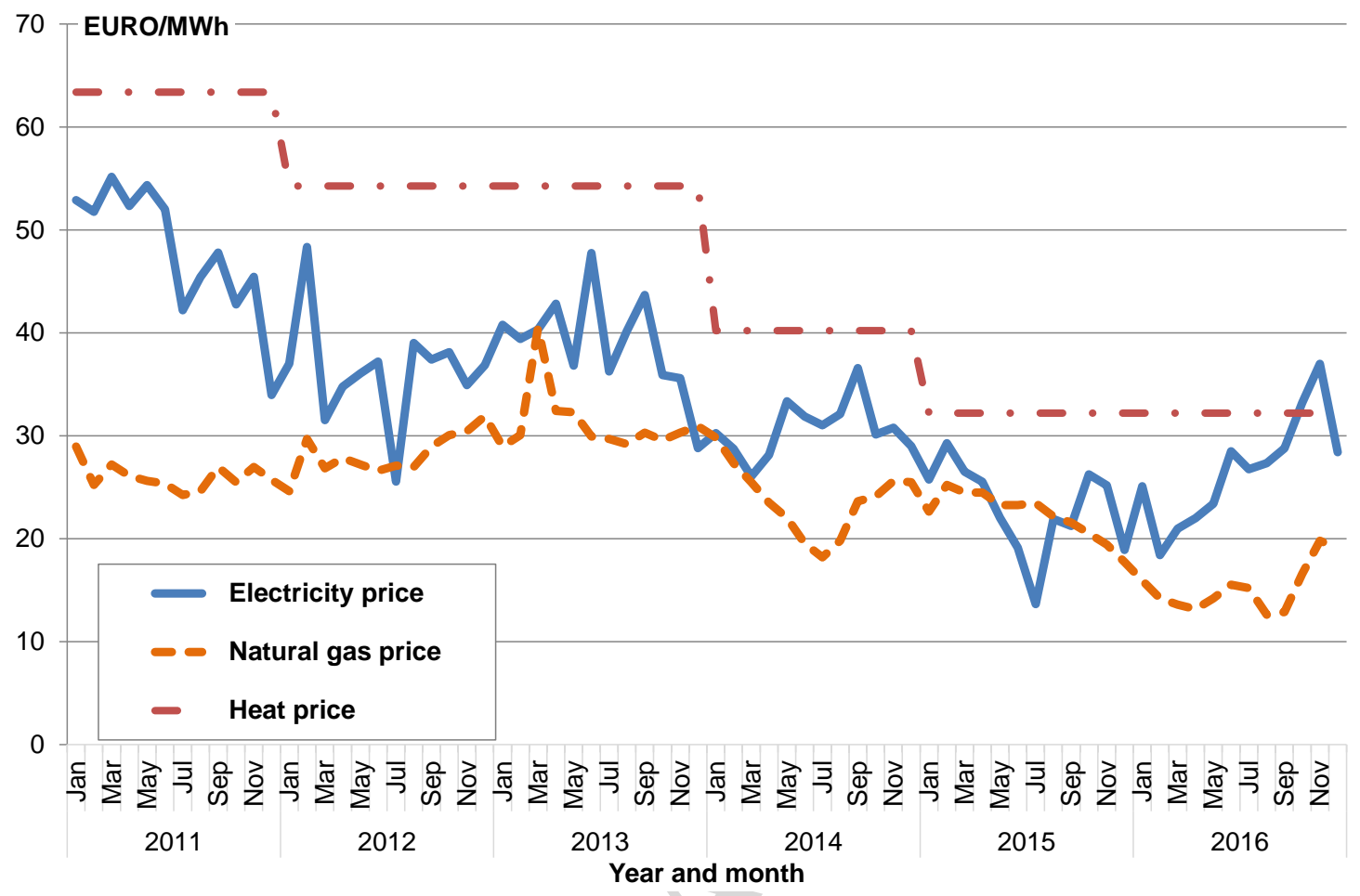

Figure 2: The historical prices of electricity, natural gas, and heat in Denmark, (Pool (2018), Gaspoint Nordic ${ }^{1}$ and Danish Energy Regulatory Authority (2017)).

2013 as in 2016. Similarly, heat prices can vary from year to year, as shown in Figure 2; notice that the heat price is for one specific heat plant, and that the prices vary across heat plants.

A large share of the heat supply in Denmark is covered by local heat production plants and distributed through a local grid. These local plants are natural monopolies and therefore monopoly regulated. The regulation is a cost-of-service regulation, with which the profits of producers must be zero, i.e. hvile-i-sig-selv, in Danish. The principle is that heat production costs are covered by the consumers, who are often co-owners. In order to ensure costs are as low as possible for the heat consumers, heat producers are obliged to produce heat at the lowest possible costs, and this is monitored by the Danish Energy Regulatory Authority. One implication of this regulation is that profit allocation within the biogas value chains can be affected by the regulation, if the energy converter produces heat.

\section{Modelling the optimal choice of value chain}

In this chapter, we follow the track of Blair et al. (1989) and consider a situation with joint profit optimisation, assuming perfect information between owners.

\footnotetext{
${ }^{1}$ Personal communication
} 


\subsection{Plant level model}

The model used to find the optimal biogas value chain, is based on a model by Jensen et al. (2017), where a mathematical optimisation model for the biogas supply chain was presented. The aim of the model is to find the optimal chain, from the farmers to the energy demands, by finding the optimal choice of e.g. plant inputs and technologies for utilising the biogas. The modelled chain can be seen in Figure 3. The supply chain is modelled such that the input side, i.e. all processes until the plant, uses a weekly time scale, while the output side, i.e. all processes from the plant, uses an hourly time scale. This allows us to capture the fluctuations of energy prices but keeping the model as small as possible. The model combines both strategic decisions regarding process sizing and tactical decisions, e.g. how much manure to use as input and when to store the biogas.

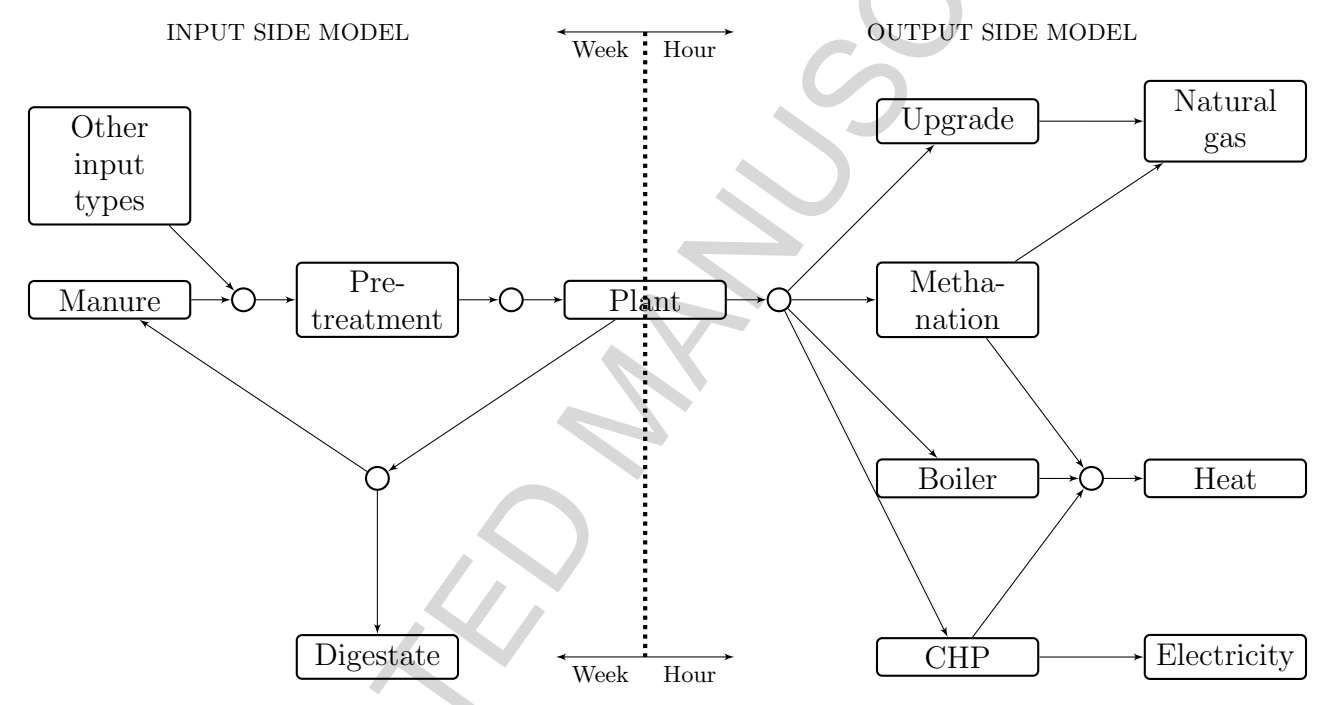

Figure 3: The biogas value chain from farmer to energy demand with the input side using a weekly time scale and the output side using an hourly time scale. The small circles represent the possibility of storages.

When biogas has been produced, the biogas plant has two products: digestate and biogas. The digestate is send back to the farmers, whose primary reason for participating is the fertiliser value of the digestate, which is better than that of manure. The biogas is sold to an energy converter. The possible energy converters in the chain include a CHP, a heat boiler, an upgrading plant, and an upgrading plant that upgrades through methanation. A traditional upgrading plant removes $\mathrm{CO}_{2}$ from the biogas so that the methane content of the resulting biomethane is similar to that of natural gas. However, an upgrading plant upgrading through methanation adds hydrogen produced through electrolysis so the $\mathrm{CO}_{2}$ from the biogas is converted to methane. Aside from the extra amount of biomethane generated during the methanation process, unlike traditional upgrading plants, process heat is generated, which can be sold for district heating.

The objective function used by Jensen et al. (2017) was profit maximisation. In this paper, the objective function is slightly different. In (Jensen et al., 2017), farmers were only included by 
receiving money for delivered manure or crops. In this paper, farmers are potential owners, and their costs must therefore be included in the total costs of the chain. For practical reasons related to profit allocation, see Section 4.3, it was decided to move transportation costs for biomasses from the biogas plant to the biomass producers.

The full model can be found in Appendix B.1; only a simplified explanation of the objective function is given here. The objective function is now to maximise the sum of profits for owners:

$$
\operatorname{Max} \sum_{o \in \mathcal{O}} \pi_{o}
$$

where $\pi_{o}$ is the profit for each owner, $o$, in the project. It is found using:

$$
\pi_{o}=I N C_{o}-C_{o} \quad \forall o \in \mathcal{O}
$$

where $I N C_{o}$ and $C_{o}$ are the income and total cost of each owner in the project. The income for each owner is found using:

$$
I N C_{o}=I N C_{o}^{\text {energy }}+I N C_{o}^{\text {support }}+I N C_{o}^{\text {digestate }} \quad \forall o \in \mathcal{O},
$$

where income from selling the energy produced is denoted by $I N C_{o}^{\text {energy }}$, support received by an owner is denoted by $I N C_{o}^{\text {support }}$, and income from selling digestate is denoted by $I N C_{o}^{\text {digestate }}$.

The total cost of each owner is found using:

$$
C_{o}=C_{o}^{O P E X}+C_{o}^{C A P E X}+C_{o}^{\text {trans }}+C_{o}^{\text {tax }}+C_{o}^{\text {digestate }} \quad \forall o \in \mathcal{O},
$$

which comprises operational expenditures, $C_{o}^{O P E X}$; capital expenditures, $C_{o}^{C A P E X}$; transportation and handling costs, $C_{o}^{\text {trans }}$; taxes paid, $C_{o}^{\text {tax }}$; and an extra cost for buying fertiliser if an agreed-upon amount of digestate is not delivered to the livestock farmers, $C_{o}^{\text {digestate }}$.

\subsection{Assumptions}

In our calculations, we follow the recommendations for socio-economic analyses of Denmark with an interest rate of $4 \%$ for all capital expenditures (CAPEX) (Danish Energy Agency, 2013), and the depreciation time is set according to data sources. If no data were available, we used a depreciation time of 20 years. Data on input and output process costs can be found in Appendix C in Table C.3 and Table C.6, and a graph on the overall CAPEXs used in the model can be seen in Figure C.1. We assume economy of scale for the biogas plant, and a constant return to scale in regard to energy converters and pretreatment of substrates.

Moreover, we assume that the farmers cover transportation costs to and from the plant. Data for transportation can be found in Table C.5. We also assume that the pretreatment of straw and deep litter is completed at the biogas plant, while the ensilage of maize and washing of the sugar 
beets is completed by the farmers, and the cutting and ensilage of sugar beet is completed by the plant. For inputs to the plant, we set the maximum dry matter content of the total feedstock to be 13\% (Jørgensen, 2013). Data for the inputs can be found in Table C.4. Finally, we assume that excess digestate can be sold for $€ 8.85$ per tonnes (Birkmose et al., 2013) and is transported according to the costs given in Table C.5.

The geographical position of the plant is set to be Northwest Denmark. Additionally, we assume that the modelled plant can expect a demand from the local heat plant in the town Vinderup that corresponds to approximately 36,000 MWh/year (Vinderup Varmeværk, 2014). Thus, this is the heat demand we use in the model, and we apply the heat price set by Vinderup Varmeværk as given by the Danish Energy Regulatory Authorities, see (Danish Energy Regulatory Authority, 2017).

Finally, 2016 is the base year for the model, which means that all prices for power, heat, and natural gas are actual prices from 2016, as are the regulatory tariffs. The power price is from the Nord Pool Spot market, which is the trading place for the Nordic power market, while the natural gas price is from Gaspoint Nordic. We apply the regulation given in Appendix A in Table A.1 and Table A.2.

\section{Profit allocation method}

In Section 5.1, we confirm the results in (Skovsgaard and Jacobsen, 2017) and (Jensen et al., 2017); the results were that biogas production can be profitable with current Danish regulation; however, value chains can be fragile without proper profit allocations between owners. We limit the cooperative in the value chain to necessary owners, with the assumption that receiving the subsidies Table A.1 and Table A.2 is preferred. These owners are livestock farmers (no wasteno support), the plant (no plant - no biogas) and the energy converter (no energy converter - no support), as shown in Figure 1. However, substrate farmers are excluded, because support can be achieved without adding substrates to the manure and substrates can be substituted. Instead, substrate farmers are paid a fixed amount for substrates corresponding to the production costs of substrates transported to the plant, plus $10 \%$ of the costs. It should be noted that there are other ways of determining prices. Examples include a method discussed by Giannoccaro et al. (2017), with which availability is handled based on biomass prices in a region, and a method discussed by Bai et al. (2012), which considered $10 \%$ too low for some substrates. However, investigating these methods was not the main focus of this paper.

\subsection{Allocation choice considerations}

Applying cooperative game theory is a way to include strategic considerations in cost and profit allocations (Tijs, 1986). Cooperative game theory was first presented by Von Neumann and Morgenstern (1944), who, with other game theorists, found it difficult to determine one unique 
solution to allocation problems. Nash (1953) proposed an axiomatic approach with which a set of conditions were stated for an appropriate allocation mechanism, and suggested that allocation mechanisms be evaluated according to this method. This approach is similar to the fairness criteria discussed in allocation literature. Formal examples of fairness criteria can be found in (Tijs, 1986) and (Hougaard, 2009). Moreover, as aforementioned, Bogetoft and Olesen (2007) presented a long list of potentially relevant criteria depending on cooperative; for example, a cooperative of pig farmers could try to avoid low market prices with an incentive that limited pig production.

In this paper, we focus on two fairness criteria: equality and individual rationality. These properties are considered in most cooperative game theoretic literature related to cost allocation (see, e.g. (Tijs, 1986; Bogetoft and Olesen, 2007; Frisk et al., 2010; Schmeidler, 1969; Megiddo, 1978; Hougaard, 2009)). However, other fairness criteria are considered as well, such as value chain risks and the risk of adverse selection.

Equality can be interpreted in many ways. Denmark has a long tradition of cooperative movements in the agricultural sector, and 'one man, one vote' was a general principle of many cooperatives. In contrast, non-cooperative game theory follows the hypothesis that a rational agent in a one-shot ultimatum game ${ }^{2}$ would offer another agent a zero share, which a rational agent would accept. However, several empirical studies show that most agents would not take an entire share, and if they did other agents would retaliate and such offers. McCain (2008) presented this as an argument for including social norms and reciprocity motives into cooperative game theory to obtain theoretical findings closer to empirical findings. Hougaard (2009) argued that equality in some form can be found in most large religions and thereby in most social norms. Therefore, we consider this fairness criterion as crucial for our evaluation of the allocation mechanisms.

An important element of homo economicus is individual rationality; an agent may query, 'Does it make sense to join the cooperative? Are there better alternatives?'. Therefore, we have chosen to focus also on individual rationality. Truett and Truett (1993) argued that one specific price between two parties could be found, and the bargaining powers of the two parties could contribute to determining this price. The bargaining powers could depend upon levels of information between the parties in the value chain (Radhakrishnan and Srinidhi, 2005), or, perhaps more importantly was the participant's dependence upon the collaboration. This dependency could be approximated by determining the best alternative for each participant.

Indeed, best alternatives (often referred to as stand-alone profits) are highly relevant to profit allocation. With individual rationality, an allocation mechanism is unstable if a profit allocated to a coalition is below an agent's stand-alone profit. Furthermore, a profit allocation is stable if it is within the core that is a set of allocations with which profits are more beneficial for all group members than stand-alone profits or profits from another coalition (Bogetoft and Olesen, 2007).

\footnotetext{
${ }^{2} \mathrm{~A}$ one-shot ultimatum game is a game in which two agents share, for example a pie. The first agent decides the division of the pie, and the other agent decides whether to reject or accept the division; this game can be extended so that if the second agent rejects the division, he or she can suggest a new division, etcetera (Gibbons, 1992).
} 
In Section 4.4, we present how individual rationality is taken into the evaluation.

\subsection{Payment schemes}

A basic principle for profit allocation is to ensure feasibility for all participating owners in the value chain - that is, to ensure that overall profits are greater than zero. However, ensuring this may be insufficient for motivating the owners, so in order to find a way to share the maximised profit between the three overall owners in this study's value chain, i.e. livestock farmers, the biogas plant and energy converters, we use the overall principles of cooperative game theory in regard to cost allocation. The owners are heterogeneous producers with large degrees of interdependence, and this implies that each party is as relevant as the others, even though one of the parties could take initiative and gain an upper hand in the negotiations. We imagine, this party could be the plant, which has the single purpose of producing biogas.

In this context, many of the allocation schemes presented in the introduction become irrelevant; however, some principles from the schemes can be reused. In Section 4.3, relevant versions of the egalitarian method, the proportionality principle, and a method inspired by the nucleolus, i.e. individual rationality, are presented. We try to understand the strategic considerations related to profit allocation and choices made by the owners when the value chain is designed, instead of considerations related to the optimal allocation mechanism. We investigate three allocation mechanisms suitable for the value chain, with which profits are distributed through prices in the chain. In Section 5, we evaluate the results of using the the model and relate these results to individual rationality. Then, we assess the potential implications in regard to possible preferred value chain and profit allocation choices.

\subsection{Allocation mechanism modelling}

After using the plant level model, profit allocation is performed. To allocate the profit between the owners, a mathematical model is used to determine the price of the products sold by each owner. The price is set using the following constraint:

$$
\pi_{o}^{C A}=\pi_{o}^{*}-\sum_{o^{\prime} \in \mathcal{O} \mathcal{T} \mathcal{O}\left(o^{\prime}, o\right)} \rho_{o^{\prime}, o}^{C A}+\sum_{o^{\prime} \in \mathcal{O} \mathcal{T} \mathcal{O}\left(o, o^{\prime}\right)} \rho_{o, o^{\prime}}^{C A} \quad \forall o \in \mathcal{O}
$$

The profit of each owner using the cost allocation method, $\pi_{o}^{C A}$, is calculated as profit obtained with the plant level model, $\pi_{o}^{*}$, minus a price paid for buying inputs, $\rho_{o^{\prime}, o}^{C A}$, plus money obtained by selling outputs, $\rho_{o, o^{\prime}}^{C A}$. The set $\mathcal{O} \mathcal{T} \mathcal{O}\left(o, o^{\prime}\right)$ indicates if owner $o$ delivers output to owner $o^{\prime}$. Moreover, as substrate farmers are not considered necessary in the chain, their profit is fixed to a percentage of their costs, but a price is also set using Equation 5.

Each of the three profit allocation mechanisms are applied using a feasibility constraint; these constraints are presented in Sections 4.3.1-4.3.3. For the proportionality and the individual ra- 
tionality mechanisms, $\lambda$ is maximised. However, the interpretation of $\lambda$ is different in the two mechanisms and is described in the corresponding sections.

\subsubsection{Full equality}

The full equality method has many names, e.g. the egalitarian method and direct equality. The principle is that all owners share the total profit equally, regardless of their total costs. The feasibility constraint for full equality allocation is:

$$
\pi_{o}^{C A}=\frac{1}{\left|o \in \mathcal{O} \backslash \mathcal{O}^{s u b}\right|} \sum_{o^{\prime} \in \mathcal{O} \backslash \mathcal{O}^{s u b}} \pi_{o^{\prime}}^{C A} \quad \forall o \in \mathcal{O} \backslash \mathcal{O}^{s u b}
$$

The profit of each owner, except substrate farmers, will be a share equal to that of each owner after payments for substrates are deducted. The share equals the total profit divided by the number of owners. The owner with the highest cost has the highest risk using this mechanism, which most likely will not be considered fair by this owner. Furthermore, there is a challenge with adverse selection as full equality requires all owners to report their costs honestly; this implies the risk that an owner would report a higher cost than what he or she actually has in order to increase his or her profit.

\subsubsection{Proportionality}

Proportionality is not as simple to consider as full equality. One needs to determine which elements profit needs to be proportional to, e.g. total costs, CAPEX or OPEX. Considering the three primary parts of the value chain, i.e. the livestock farmers, the plant and the energy converters, it is difficult to find one common parameter or variable for all parts of the value chain that does not present knowledge-sharing challenges. In this paper, we chose to use the cost of each owner from the plant level model. This choice implies that each owner has a cost assigned, and this is why transportation costs are added to the farmers, unlike in (Jensen et al., 2017).

The feasibility constraint for proportionality allocation is:

$$
\pi_{o}^{C A}=\lambda C_{o}^{*} \quad \forall o \in \mathcal{O} \backslash \mathcal{O}^{s u b}
$$

where $\lambda$ is the percentage of the cost that can be covered for each non-substrate owner. This mechanism has a higher risk of adverse selection, as it gives an incentive to owners to boost their own costs in order to achieve a higher share of the total profit. Moreover, the method does not reflect that all three parts of the value chain are necessary for achieving support.

\subsubsection{Individual rationality}

The final mechanism that we apply is inspired by the maximin profit allocation, the nucleolus mechanism. In the traditional nucleolus mechanism, all combinations of participating owners and their alternative profits are used for the allocation, and the profit for each owner is found by 
maximising each distance from each obtained profit to each alternative profit for all subsets of participating owners. Nucleolus allocation is per definition in the core. The owners when applying the traditional nucleolus mechanism are typically all the same type; see, for example, (Frisk et al., 2010), and the operability of the collaboration is therefore not one in which each owner is relied upon individually. In regards to this study, the owners rely on each other to ensure the biogas chain operating, so the nucleolus mechanism can not be directly applied.

Instead of considering all possible coalitions, as in the nucleolus mechanism, we consider the revenue gain of each owner independently by maximising each distance from each obtained profit to each alternative profit that could be obtained through a lack of participation. This ensures that the obtained solution is within the core, which means that all owners benefits the most as part of the chain. The allocation mechanism ensures that all owners get the same revenue gain. This is in contrast to the nucleolus mechanism, where coalitions with the smallest revenue gains get the greatest revenue gains, which means that not necessarily all coalitions end up with the same revenue gain.

The feasibility constraint for individual rationality allocation is:

$$
\pi_{o}^{C A}-\pi_{o}^{A L T}=\lambda \quad \forall o \in \mathcal{O} \backslash \mathcal{O}^{s u b},
$$

where $\lambda$ is the participation gain for all non-substrate owners, and $\pi_{o}^{A L T}$ is a reported alternative profit for each owner, o. This allocation mechanism may seem fair as it is more equal than the proportionality mechanism and considers more individual properties than the full equality mechanism; however, costs are not directly considered. Moreover, there is a lack of transparency and a necessarily high level of information is needed in order to calculate the allocation; the latter allows dishonest reports regarding each owner's best alternative.

\subsection{Inclusion of individual rationality}

In the value chain, the sample space of best alternatives is large; in order to decrease it to a reasonable amount of calculations, we exploit having reduced the owner group to the three parties. Some of the owners can, to some extent, be replaced after investments, though this is done at the expense of the overall profit. The approach is to consider the alternatives for the individual owners and the entire value chain. As capital costs are extensive parts of total costs in biogas value chains, both choices before investments (ex ante) and after investments (ex post) are considered, as ex post bargaining power can affect the preferences of each owner in regard to both the value chain configuration and the preferred allocation mechanisms before investments. We evaluate the alternatives in Section 5, starting with the results presented in Table 1. In the calculation for individual rationality profit allocation, the results presented in Table 5 are also applied.

For livestock farmers, we assume that the best alternative is to deliver manure to another biogas plant. The farmers could choose to apply manure directly to the fields, but this would not 


\begin{tabular}{lll}
\hline & Before investments & After investments \\
\hline \hline Livestock farmer & $\begin{array}{l}\text { Deliver manure to another biogas } \\
\text { plant }\end{array}$ & $\begin{array}{l}\text { Deliver manure to another biogas } \\
\text { plant }\end{array}$ \\
\hline Plant & Invest capital with a 4\% interest rate & Sunk costs \\
\hline Energy converter, CHP & Biomass-based heat boiler & $\begin{array}{l}\text { Sunk costs and a biomass-based heat } \\
\text { boiler }\end{array}$ \\
$\begin{array}{l}\text { Energy converter, } \\
\text { upgrade }\end{array}$ & Invest capital with a 4\% interest rate & Sunk costs \\
\hline
\end{tabular}

Table 1: The stand-alone profits

provide the additional fertiliser value from the digestate. A common payment for manure is one in which the biogas plant collects manure and delivers digestate for free; in Table 5, this alternative is presented as a zero profit, as the fertiliser value is not included in the calculations.

For the biogas plant, several options exist, but for this analysis, it is assumed that the plant invests its capital in safe investments at an interest rate that corresponds to the socio-economic interest rate before investments, and that the plant has sunk costs after investment. However, it is just as likely that the plant would try out other options, especially ex post.

In order to determine the best alternatives for the energy converters, we need to make some overall assumptions. The plant level model in Section 3 allows different technology choices: upgrading technologies, a heat and power plants, and a heat boiler. With current regulation, it is unlikely that the optimal choice is to produce heat with biogas, so this alternative was not considered further. Moreover, with regard to coverage of heat and power demands, there are two different markets that need to be considered. As the power market is highly competitive in Denmark, a CHP is, in many cases, only a viable option if it is fuelled by a supported fuel. In most cases, the energy converter would have to find an alternative to the heat production if the biogas-based CHP is dismissed. Therefore, we assume that the best alternative to a biogas-based CHP is a biomass-based heat boiler, both before and after investments. Finally, for upgrading, we assume that the energy converter can freely choose to either supply or not supply the heat demand.

\begin{tabular}{lll}
\hline & Before investments & After investments \\
\hline \hline Livestock farmer & Longer transportation distance & Longer transportation distance \\
Substrate farmer & Other substrate & Other substrate and sunk costs in pretreatments \\
Energy converter & Other energy converter & Other energy converter and new investments \\
\hline
\end{tabular}

Table 2: The alternative profits for the value chain if an owner retracts

The overall principle for alternatives in the value chain is that the plant cannot be substituted, if the value chain should remain. This gives the plant a good position with regard to bargaining power. We assume that all other parties can be substituted at the expense of total profits in the value chain. 
The content of Table 2 is derived using the plant level model. For the livestock farmers, the assumption that the farmers are a cooperative, and not a single farmer, is exploited. It is therefore realistic that some farmers in the cooperative could decide to choose another alternative and not join the value chain. For simplicity, we assume, that one third of the livestock farmers leave the livestock farmer cooperative. New data on manure access is then fed into the model, and a new optimal solution is found with a lower profit. Finally, for the substrate farmers and the energy converters, the model is run with the restriction of not choosing the optimal choice, first for the substrate and second for the energy converter. Thereby, a new optimal solution and corresponding alternative profits are found.

\section{Application and results}

\subsection{Optimal value chain}

In this section, we consider a base scenario in which the model determines the optimal size of the plant, the optimal substrates to use for production, and the optimal energy converter - considering the substrate, transportation, and investment costs in relation to the potential income. The plant level model is a detailed model, and in order to ensure a short calculation time, optimisation is done for one year, and investment costs are estimated as yearly costs. Therefore, the model does not consider price and cost variations over several years. As energy prices for both the input and the output side of the model significantly influence the optimal investment choice, and these prices can vary significantly, we run a number of sensitivity analyses.

First, we consider the electricity costs that can influence whether it is profitable to use methanation. As the PSO is phased out in 2022, a scenario was created in which the PSO is zero. This scenario is called PSO zero. Second, we consider the natural gas price. The natural gas price is quite low in the base year, compared to previous years, so the optimal solution could change with the natural gas price. Therefore, we use the time series for the natural gas price from 2013 - when the prices were almost double the prices in 2016 - to see the effects of the natural gas prices. In the scenario called NG high, we use the natural gas price from 2013 and all other data was set to be equal to the data in the base scenario. An overview of the scenarios can be seen in Table 3.

The energy system is, to a great extent, interrelated; when natural gas prices are high, one can expect that this will be reflected in heat prices in areas where natural gas is used as fuel. For example, as Denmark becomes more dependent on renewable energy, such as wind, solar, and hydro power, it can be expected that the electricity price is less dependent on the natural gas price - except when renewable energy is insufficient to meet the electricity demand. Therefore, we expect less convergence between the natural gas and electricity price; however, due to variations in weather conditions, we can also expect certain variations in the electricity price. Finally, in the second group of scenarios, i.e. in the 2013 and 2015 scenarios, we test the model in regard to a group of energy costs and prices. In these scenarios, we use the fundamental costs of technologies 


\begin{tabular}{lcccccc}
\hline & \multicolumn{2}{c}{ Electricity cost } & \multicolumn{2}{c}{ Natural gas price } & \multicolumn{2}{c}{ Heat price } \\
Scenario & Average $€ / \mathrm{MWh}$ & Level & Average $€ / M W h$ & Level & $€ /$ MWh & Level \\
\hline \hline Base & 26.5 & High & 15.2 & Low & 32.2 & Low \\
PSO zero & 15.1 & Low & 15.2 & Low & 32.2 & Low \\
NG high & 26.5 & High & 31.4 & High & 32.2 & Low \\
\hline \hline $\mathbf{2 0 1 5}$ & 22.6 & Medium & 22.3 & Medium & 32.2 & Low \\
$\mathbf{2 0 1 3}$ & 24.0 & Semi-High & 31.4 & High & 54.3 & High \\
\hline
\end{tabular}

Table 3: The tested scenarios

and inputs from the base scenario, but use the electricity price + taxes and fees, and the natural gas and the heat prices for 2013 and 2015.

\subsubsection{Results and preliminary conclusions}

The results from using the plant level model is seen in Table 4. The biogas plant is as large as possible for all scenarios, i.e. 600,000 tonnes of biogas per year is produced, and the preferred substrate for all cases is deep litter.

\begin{tabular}{llccccc}
\hline & Unit & Base & PSO zero & NG high & $\mathbf{2 0 1 5}$ & $\mathbf{2 0 1 3}$ \\
\hline \hline Netincome & $\mathrm{m} \in$ & 6.31 & 6.31 & 9.56 & 6.72 & 8.05 \\
Total cost & $\mathrm{m} \in$ & 9.67 & 9.67 & 18.19 & 16.82 & 19.02 \\
Total income & $\mathrm{m} €$ & 15.98 & 15.98 & 27.75 & 23.55 & 27.07 \\
Support & $\mathrm{m} €$ & 11.41 & 11.41 & 13.44 & 13.43 & 13.44 \\
\hline Input & & & & & & $0.0 \%$ \\
\hline Cow slurry (manure) & \% of input & $0.0 \%$ & $0.0 \%$ & $0.0 \%$ & $0.0 \%$ & $69.4 \%$ \\
Pig slurry (manure) & \% of input & $69.4 \%$ & $69.4 \%$ & $69.4 \%$ & $69.4 \%$ & $30.6 \%$ \\
Deep litter & \% of input & $30.6 \%$ & $30.6 \%$ & $30.6 \%$ & $30.6 \%$ & \\
\hline Output & & & & & & \\
\hline Energy converter & Type & CHP & CHP & Methanation & Methanation & Methanation \\
Capacity of energy converter & MW & 9.9 & 9.9 & 19.8 & 20.3 & 20.4 \\
Energy produced & GWh & 116 & 116 & 415 & 414 & 415 \\
\hline
\end{tabular}

Table 4: The scenario results

In the base scenario, a combined heat and power plant (the combined cycle gas turbine) is installed. The type of energy converter installed seems to depend mainly upon the natural gas price as the PSO zero scenario results in a combined heat and power plant being installed as the energy converter, while the upgrading using methanation is preferred for all cases with higher natural gas prices than in the base scenario. Moreover, in the scenarios with higher natural gas 
prices, the total profit is larger than in the base case.

The amount of support received in each scenario also depends upon the energy converter. The received support is lowest in the base scenario; however, the support received per unit of energy is lower using methanation. In the scenarios using a CHP, the support is $€ 97.93$ per $\mathrm{MWh}$, and in the scenarios using methanation, the support is $€ 32.41$ per MWh, so for less support, more energy is provided. The methanation process, besides receiving less support per unit of energy, also pays taxes in the form of an electricity tax on used electricity and excess heat tax.

The decision of biogas producers to upgrade in later years, could be explained by an expectation of higher gas prices in the future - an expectation shared by the Danish Energy Agency (Danish Energy Agency, 2012b, 2017). One should be aware that although the model chooses the methanation technology, this technology is not fully commercialised yet.

The NG high scenario gives the highest profit across all the scenarios by only changing one parameter. We consider this scenario further as a relevant alternative to the base scenario in the analysis presented in the following sections.

\subsection{Results of applying the allocation mechanisms}

In this section, we assess three profit allocation mechanisms in relation to viability. We then consider the implications of these allocation methods with regard to the individual choices in the value chain.

Based on the results from the plant level model, we use the base scenario and the NG high scenario to discuss the effects of applying the following allocation mechanisms full equality, proportionality and individual rationality. In order to calculate the individual rationality allocation, we need to know the alternative profits for each owner in the chain.

Applying the assumptions stated in Section 4.4, we calculate the alternative profits for each owner in the chain, should they decide not to participate in the value chain. The results are presented in Table 5 .

\begin{tabular}{llc}
\hline & \multicolumn{2}{c}{ Before investments } \\
\cline { 2 - 3 } & Description & Alternative profits \\
\hline \hline Livestock farmer & Other biogas plant & $0 € /$ ton \\
\hline Plant & No investment, base scenario & $0.07 \mathrm{~m} € / \mathrm{y}$ \\
\hline Energy converter, CHP & No investment, NG high scenario & $0.07 \mathrm{~m} € / \mathrm{y}$ \\
Energy converter, methanation & Heat boiler, base scenario & $0.53 \mathrm{~m} € / \mathrm{y}$ \\
\hline
\end{tabular}

Table 5: The ex ante alternative profits for the owners in the value chain 


\subsubsection{Results from the profit allocation}

As seen in Figure 4, the profit is allocated quite differently depending on the chosen profit allocation mechanism. For the proportionality mechanism, the allocation would most likely not be considered equal in any of the scenarios.

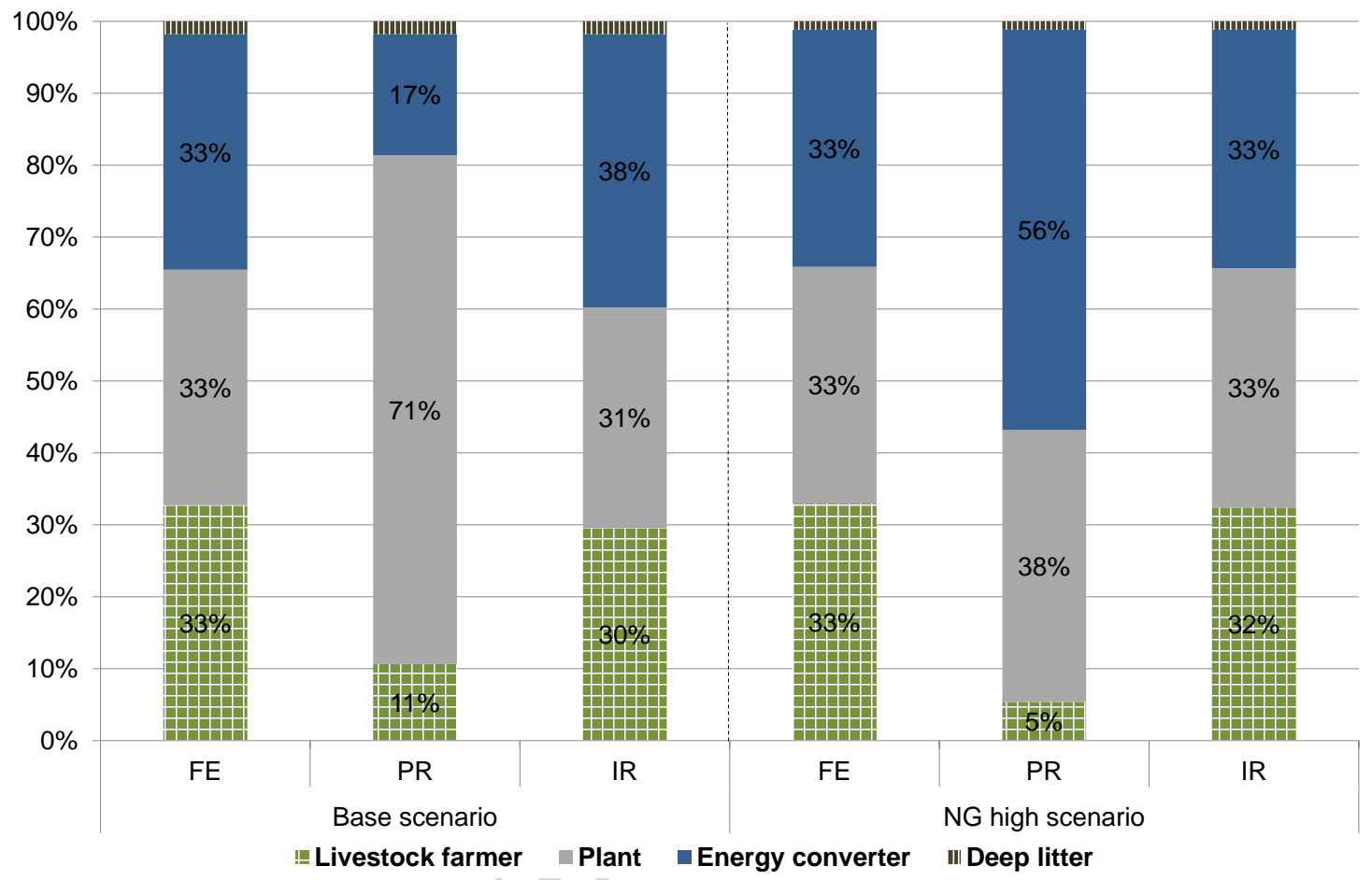

Figure 4: The percentage of total profit for each owner in all scenarios

It is obvious that the plant owner would prefer the proportionality distribution in both scenarios as this is where the highest percentage of profits can be gained. This is underlined by the results presented in Table 6, showing the intermediate prices within the value chain and the profits for each owner under the selected scenarios for each type of allocation described in Section 4.3.

We find that the biogas plant would prefer proportional allocation in both scenarios, while the livestock farmer would always prefer full equality. More specifically, we find that in the base scenario, the livestock farmer and the energy converter - as opposed to the plant owner-would prefer the full equality or individual rationality mechanism, both of which would give them a higher total profit. In the NG high scenario, both the biogas plant and the energy converter would prefer the proportionality mechanism. The change in results for the energy converter's perspective can be explained by the higher costs related to methanation, which is only reflected in proportional allocation. The livestock farmer would still prefer the full equality or individual rationality mechanism.

In the base scenario, the highest biogas price is found using proportional allocation. This is where the plant would gain the highest profit even though the total profit is lower compared 


\begin{tabular}{|c|c|c|c|c|c|c|c|}
\hline & \multirow[b]{2}{*}{ Unit } & \multicolumn{3}{|c|}{ Base scenario } & \multicolumn{3}{|c|}{ NG high scenario } \\
\hline & & FE & PR & IR & FE & $\mathbf{P R}$ & IR \\
\hline Netincome & $\mathrm{m} € / \mathrm{y}$ & 6.31 & 6.31 & 6.31 & 9.56 & 9.56 & 9.56 \\
\hline - Livestock farmer & $\mathrm{m} € / \mathrm{y}$ & 2.06 & 0.67 & 1.86 & 3.15 & 0.51 & 3.10 \\
\hline - Deep litter & $\mathrm{m} € / \mathrm{y}$ & 0.11 & 0.11 & 0.11 & 0.11 & 0.11 & 0.11 \\
\hline - Plant & $\mathrm{m} € / \mathrm{y}$ & 2.06 & 4.46 & 1.94 & 3.15 & 3.62 & 3.18 \\
\hline - Energy converter & $\mathrm{m} € / \mathrm{y}$ & 2.06 & 1.06 & 2.40 & 3.15 & & 3.17 \\
\hline \multicolumn{8}{|c|}{ Price per unit sold } \\
\hline Manure & $€ /$ ton & 7.18 & 3.83 & 6.70 & 70 & 3.45 & 9.66 \\
\hline Deep litter & $€ /$ ton & 6.75 & 6.75 & 6.75 & 6.75 & 6.75 & 6.75 \\
\hline Biogas & $€ / \mathrm{MWh}$ & 63.48 & 69.29 & 61.56 & 78.25 & 65.68 & 78.14 \\
\hline
\end{tabular}

Table 6: Results from the allocation using the full equality (FE), proportionality (PR), and individual rationality (IR) mechanisms

with the NG high scenario. In the NG high scenario, the proportionality mechanism results in the lowest cost of biogas because the highest profit with this mechanism is given to the energy converter, meaning that less money has to be paid to the rest of the chain.

\subsection{Ex ante considerations}

Following the notions from Bogetoft and Olesen (2007) and Hougaard (2009) regarding individual rationality in profit allocation, we examine whether our profit allocation can be considered to be in the core.

The individual owners in the value chain are expected to consider their own gain from participating in the value chain rather than doing something else. In order to reach a viable value chain, it is necessary to find a viable profit allocation, both to assure investments (ex ante) and to assure that the most important partners stay in the value chain (ex post).

The owners also have to consider the risk that other owners will retract from the coalition, and they must consider how this would affect profits in the value chain both before and after investments are made. This risk influences both expected profits for the value chain and the bargaining power of each owner when the allocation of the profits is negotiated.

Next, we distinguish between ex ante and ex post considerations, as risks change depending on whether investments have already been made or not. If one owner retracts from the value chain before investments, the remaining value chain will have to find an alternative owner, and profits will be reduced in comparison with the results in Table 4 . The new profits obtained are given in Table 7 as the percentage of the optimal profit from the base and NG high scenarios that was presented in Table 4. 


\begin{tabular}{|c|c|c|c|c|}
\hline & \multicolumn{2}{|c|}{ Base scenario } & \multicolumn{2}{|c|}{ NG high scenario } \\
\hline & Description & $\begin{array}{c}\text { Percentage } \\
\text { of profit }\end{array}$ & Description & $\begin{array}{c}\text { Percentage } \\
\text { of profit }\end{array}$ \\
\hline Livestock farmer & $\begin{array}{l}\text { Longer transport } \\
\text { distance }\end{array}$ & $97 \%$ & $\begin{array}{l}\text { Longer transport } \\
\text { distance }\end{array}$ & $98 \%$ \\
\hline Substrate farmer & Straw & $55 \%$ & Straw and sugar beet & $75 \%$ \\
\hline Energy converter & Water scrubbing & $63 \%$ & Water scrubbing & $56 \%$ \\
\hline
\end{tabular}

Table 7: The effects on profit in the biogas value chain when an owner retracts before investments

We find that the effect of the livestock farmer on profits is small overall, as the profit for the entire value chain would only be affected marginally if $1 / 3$ of the optimal livestock farmers decided to withdraw from the coalition. This puts the coalition of farmers in a weak negotiating position. In a value chain with upgrading plants, the livestock farmers could face the risk that the other parties would agree on a proportional allocation principle, leaving the livestock farmers with a low profit share since their costs are also quite low.

The relationship between the biogas plant and energy converter is more complicated, and the risks are high on both sides. In the base scenario where natural gas prices are low, the preferred solution for the entire value chain would be direct usage in a local CHP; the best alternative (upgrading by water scrubbing) would result in a significantly lower profit. The CHP has a fairly good alternative to biogas in the form of a biomass-based heat boiler. This could put pressure on the biogas plant to turn away from proportional allocation towards full equality or the individual rationality profit allocation preferred by the CHP.

In the NG high scenario, upgrading with methanation is the preferred choice for the energy converter, and the best alternative is water scrubbing, with a total profit just above the result from the base scenario (approximately $€ 5.35$ million per year). This is, however, quite a reduction compared to the profits from methanation, so the value chain has an interest in methanation.

\subsection{Ex post risks affecting investment decisions}

When investments have already been made, both the biogas plant and the energy converter will lose money due to sunk costs if one member of the value chain decides to withdraw from the collaboration. As it is displayed in Table 8, the biogas plant risks the largest sunk costs if investments are made for direct consumption in a local CHP. At the same time, sunk costs are lower for the CHP investor.

If instead the biogas plant has made a coalition with an upgrading plant, the energy converter will face the highest sunk costs. Furthermore, the upgrading plant needs biogas to operate, while the biogas plant will probably be able to find alternative options. This leaves the biogas plant in a better negotiating position before and, in particular, after investments. 


\begin{tabular}{llc}
\hline & \multicolumn{2}{c}{ After investments } \\
\cline { 2 - 3 } & Description & Alternative profit \\
\hline \hline Livestock farmer & Other biogas plant & $0 € /$ ton \\
\hline \multirow{2}{*}{ Plant } & Sunk cost, base scenario & $-1.82 \mathrm{~m} € / \mathrm{y}$ \\
\hline Energy converter, CHP & Sunk cost, NG high scenario & $-1.67 \mathrm{~m} € / \mathrm{y}$ \\
Energy converter, methanation & Sunk cost CHP plus heat boiler profit & $-1.26 \mathrm{~m} € / \mathrm{y}$ \\
\hline
\end{tabular}

Table 8: Ex post alternative profits for the owners in the value chain

The livestock farmers would have no direct costs from leaving the coalition unless they had signed a contract ex ante that imposed a cost in cases of ex post defection. If a proportional allocation mechanism was decided ex ante, resulting in low profit shares for the livestock farmers, there would be a credible risk that the livestock farmers would find this distribution of profits too unequal and unfair. This could bring a risk of defection, as a cost-effective option for the livestock farmers; or, if defection costs were increased due to contracts, there could be a risk of adverse selection, where farmers might pretend that costs were higher than they were or might be more likely to deliver manure at a lower dry-matter content than promised.

\begin{tabular}{|c|c|c|c|c|}
\hline & \multicolumn{2}{|c|}{ Base } & \multicolumn{2}{|c|}{ NG high } \\
\hline & Description & $\begin{array}{l}\text { Percentage } \\
\text { of profit }\end{array}$ & Description & $\begin{array}{c}\text { Percentage } \\
\text { of profit }\end{array}$ \\
\hline Livestock farmer & $\begin{array}{l}\text { Longer transport } \\
\text { distance }\end{array}$ & $97 \%$ & $\begin{array}{l}\text { Longer transport } \\
\text { distance }\end{array}$ & $98 \%$ \\
\hline Substrate farmer & Straw and sunk costs & $51 \%$ & $\begin{array}{l}\text { Straw, sugar beet and } \\
\text { sunk costs }\end{array}$ & $72 \%$ \\
\hline Energy converter & $\begin{array}{l}\text { Water scrubbing and } \\
\text { sunk costs }\end{array}$ & $47 \%$ & $\begin{array}{l}\text { Water scrubbing and } \\
\text { sunk costs }\end{array}$ & $45 \%$ \\
\hline
\end{tabular}

Table 9: The effects on profit in the biogas value chain when an owner retracts after investments

The best alternative to deep litter is to use straw as an additional substrate. This would result in a significantly lower profit for the value chain, especially if investments have already been made. Since the deep litter farmer is faced with no costs for defecting and may not even be bound by any contracts, a reasonable payment to the deep litter farmer is necessary even though cheaper alternatives than straw might be available. Hence, the $10 \%$ cost coverage may not be sufficient. 


\section{Policy insights}

Danish biogas production has increased to a remarkably extent the later years, and there have been two tendencies: 1) most plants decide to upgrade, and 2) the larger plants especially have difficulties in finding enough farmers who will commit to delivering the manure needed as input. We argue that our results can help to explain these tendencies.

\subsection{Implications for farmer involvement}

The best alternative for livestock farmers, given in Tables 5 and 8, is a payment commonly used for the farmers to deliver manure to the biogas plant. They get their manure treated at no cost, and in return, they are paid nothing (Lemvig Biogas Plant, 2017). This alternative profit is lower than the profit they could achieve by staying in the value chain using any of the profit allocation mechanisms we have chosen to investigate. Furthermore, an individual farmer is often replaceable at low costs, cf. Tables 7 and 9. This leaves the farmers in a bad negotiating position and might prompt them as a group to accept something in line with the proportionality allocation mechanism, even if it seems unfair. Alternatively, they may try to become co-owners of the plant to attain more of the profit, and this corresponds well with observable trends in Denmark, where it is common for farmers to be co-owners. If the farmers find it difficult to raise capital to become co-owners, they may not be interested in committing themselves to deliver manure at a low price, simply because they find the profit allocation to be unfair and, therefore, not worth any risk.

Policy makers could affect these challenges by moving some of the support from energy converters to the beginning of the chain. While Danish biogas support is currently focused on the energy output, regulators in Norway, for example, have focused some of the support on the input side by giving support to the manure treatment (Lyng et al., 2018). This could increase the alternative profit for the farmers, and thereby their bargaining power, in cost allocation discussions.

\subsection{Implications for the choice of value chain design}

From the results in Section 5, we find that several considerations should be taken for the choice of value chain design. First, it is relevant to make sure there is an actual heat demand. The fact that new investments have been made primarily in upgrading plants could be due to a low heating demand. Similar arguments could apply for existing plants, combined with disagreements on the profit sharing when existing contracts are to be renegotiated.

The next few considerations involve the expected profits for the total value chain. Our results have shown that high gas prices would make upgrading the preferred choice, while low gas prices would favour a value chain ending with a CHP. As the prognosis for the natural gas price shows an increase, it is logical to assume that new investments in biogas plants could be based on positive projections for the natural gas price, implying that upgrading would be the preferred choice (Danish Energy Agency, 2012b, 2017). 
The actual development in the natural gas price has, however, shown a downward trend in recent years due to the financial crisis, shale gas (primarily in the US) and an increase in renewable energy substituting gas-driven CHPs. It is therefore likely that some biogas producers would be inclined to choose the CHP solution. A reason why so few have actually made that decision could be strategic considerations. An analysis including both ex ante and ex post considerations shows that the owners of a biogas plant using backward induction would most likely prefer to join a value chain design with upgrading, even if expected profits for the total value prove to be higher with a CHP. This can be understood by examining how profits can actually be expected to be allocated based on the value chain design when both ex ante and ex post bargaining powers are accounted for.

If a CHP is installed to satisfy a heat demand, the best alternative to biogas is to install a biomass-based heat boiler. This alternative gives the CHP good ex ante bargaining power. After investments are made, both the biogas plant and the CHP will lose if one of the parties chooses to defect and break the chain; however, the energy monopoly regulator, the Danish Energy Regulatory Authority, may force the energy converter to pay less for the biogas than first agreed upon, thereby reducing the opportunities for profit for the biogas plant (see, for example, (Danish Energy Regulatory Authority, 1999)).

This means that a biogas plant will be reluctant to involve itself in a value chain with direct consumption in a CHP, even though the resulting feed-in tariff on produced electricity could yield the highest potential profit for the value chain at the lowest risk. Backward induction shows that the proportional allocation will most likely be discarded either ex ante or ex post for the benefit of an allocation mechanism more in line with full equality or individual rationality, following the preferences of the energy converter.

Conversely, if the value chain ends with an upgrading plant, it will be the biogas plant that has the upper hand. For an investor, an upgrading plant could be very profitable, particularly if a $4 \%$ discount rate is the best alternative, while from the perspective of the biogas plant, an upgrading facility could add good profits with the right profit allocation. An ex post deviation from the value chain would result in significant sunk costs for the upgrading plant's owner, as the capacity cannot be used for anything else than biogas. The biogas plant would also have a risk of sunk costs, but but its chances are better than those of the upgrading plant for finding a good alternative usage of the capacity, such as for heat and power production or another upgrading plant. This puts the biogas plant in a much better ex post negotiating position, compared to the negotiations with a local CHP. Furthermore, it is more likely that the biogas and the upgrading plant can agree on a profit allocation principle in line with the proportional allocation, as this is the preferred allocation for both. All of these arguments are in favour of upgrading when looking from the perspective of the biogas plant, which is likely to be the initiator of the project.

If policy makers intend to increase the number of value chains ending with direct consumption, a policy implication from this analysis is that they can consider decreasing support for upgrading 
(or increasing support for direct consumption). If they instead give preference to upgrading, this analysis indicates that the status quo in regulation may not change the pattern in value chain designs even, if natural gas prices continue to stay low in the near future.

\section{Conclusion}

Danish biogas production has developed remarkably since regulation was changed so upgraded biogas was supported at the same level as biogas applied directly in a local CHP. Several new plants have been built, where most plant owners have chosen to upgrade the biogas, and older plants are also upgrading. New biogas plants, however, tend to face barriers in achieving enough contracts with livestock farmers who will supply the biogas plant with manure.

We have combined the optimisation of the biogas value chain with applied game theory to understand these observations. We started with profit allocation, focusing on the fairness criteria og equality and individual rationality, and we then discussed the application of backward induction to analyse the strategic approaches to the investment options.

We have found that this approach broaden the perspective of the strategic considerations made by the essential parties in the biogas value chain but also on the empirical evidence we found. To our knowledge, the approach has not yet been applied to a biogas value chain analysis; in fact, the best example we could find for an applied analysis was the study of Hubert and Ikonnikova (2011), which considers the bargaining power in the Eurasian gas market transit. Hubert and Ikonnikova (2011) apply allocation mechanisms as an indicator of bargaining power, whereas we consider the results as possible outcomes of a negotiation. The likelihood of these outcomes depends on the bargaining power of each participant, which is assessed through the potential alternatives before and after investments - assuming individual rationality.

The optimal configuration of the biogas value chain is found using a mixed integer optimisation model. The optimal solution is to build a large biogas plant with a high share of manure and a cheap supplementary input substrate in our case, deep litter. The optimal choice of energy converter is a local CHP when natural gas prices are low and an upgrading facility using methanation when natural gas prices are high.

Using the optimal configuration, we implemented three mechanisms for allocating the profit: full equality, proportionality, and individual rationality. Comparing the solutions between using a CHP and an upgrading facility as the energy converter, the following conclusions are drawn.

First, farmers have low bargaining power, which can result in low profit shares and, eventually, a lack of attendance or defection if the farmers have already agreed on attendance. Policy makers could overcome this obstacle by moving some of the support from the energy converters to the farmers, thereby increasing the bargaining power of the farmers.

Second, the negotiating position of the biogas plant is the best if the energy converter is an upgrading plant and is relatively bad if the energy converter is a CHP. It is also likely that the 
plant will be able to agree on the allocation mechanism with an upgrading plant; at least, they could do so by looking at the three mechanisms applied in this study. These points can help to explain the clear preference for upgrading we find empirically. If policy makers were to change this development, they could decrease the support given to biogas upgrading relative to the support given for direct consumption of biogas.

Overall, we have found several arguments, based on theory and our modelling, that support the observations found regarding the choices made by Danish biogas value chains in recent years.

\section{Acknowledgements}

We would like to thank Henrik Klinge Jacobsen and Catharina Wiese for their valuable comments and discussions. In addition, we would like to thank the reviewers from Energy Economics for their comments such that the overall quality of the article could be improved. This work was supported by the Danish Council for Strategic Research (DSF), under the 'Strategic Research in Sustainable Energy and Environment' research programme (Grant number: 12-132631, 'Optimisation of Value Chains for Biogas Production in Denmark (BioChain)'). The authors are responsible for the content of this publication.

\section{References}

Abildgaard, L., 2017. Personal communication.

Bai, Y., Ouyang, Y., Pang, J.S., 2012. Biofuel supply chain design under competitive agricultural land use and feedstock market equilibrium. Energy Economics 34, 1623-1633. URL: http://dx.doi.org/10.1016/ j.eneco.2012.01.003, doi:10.1016/j.eneco.2012.01.003.

Birkmose, T., Hjort-Gregersen, K., Stefanek, K., 2013. Biomasse til biogasanlæg i Danmark - på kort og langt sigt (Biomasses for biogas plants in Denmark - in the short and long run). Technical Report april. URL: http:// www.ens.dk/sites/ens.dk/files/undergrund-forsyning/vedvarende-energi/bioenergi/biogas-taskforce/ rapporter_taskforce/biomasser_til_biogasanlaeg.pdf.

Blair, R.D., Kaserman, D.L., Romano, R.E., 1989. A Pedagogical Treatment of Bilateral Monopoly. Southern Economic Journal 55, 831. URL: http://www.jstor.org/stable/1059465?origin=crossref, doi:10.2307/1059465.

Bogetoft, P., Olesen, H.B., 2007. Cooperatives and payment schemes; Lessons from theory and examples from Danish agriculture. Copenhagen Business School Press.

Boldrin, A., Baral, K.R., Fitamo, T., Vazifehkhoran, A.H., Jensen, I.G., Kjærgaard, I., Lyng, K.A., Nguyen, Q.V., Nielsen, L.S., Triolo, J.M., 2016. Optimized biogas production from co-digestion of sugar beet with pig slurry: integrating energy, GHG and economic accounting. Energy 112, 606-617. URL: http://dx.doi.org/10.1016/ j.energy.2016.06.068, doi:10.1016/j.energy.2016.06.068.

Bowley, A.L., 1928. Bilateral Monopoly. The Economic Journal 38, 651. URL: http://www.jstor.org/stable/ 2224123 ?origin=crossref, doi:10.2307/2224123.

Brudermann, T., Mitterhuber, C., Posch, A., 2015. Agricultural biogas plants - A systematic analysis of strengths, weaknesses, opportunities and threats. Energy Policy 76, 107-111. URL: http://www.sciencedirect.com/science/ article/pii/S0301421514006302.

Buzzell, R.D., 1983. Is vertical integration profitable? Harvard Business Review . 
Danish Energy Agency, 2012a. Begraensning for brug af majs og andre energiafgrøder til produktion af biogas (limitations on the usage of energy crops in biogas production). URL: https://ens.dk/sites/ens.dk/files/ Bioenergi/energiafgroeder_begraensning_majs.pdf.

Danish Energy Agency, 2012b. Danmarks Energifremskrivning 2012 (Danish energy projection 2012). October 11 ed.

Danish Energy Agency, 2012c. Technology data for energy plants. May. doi:ISBN : 978-87-7844-940-5, arXiv: ISBNwww: $978-87-7844-931-3$.

Danish Energy Agency, 2013. Opdateret tillægsblad om kalkulationsrente, levetid og reference (Updated suplement for the guidence for socioeconomic analysis). URL: https://ens.dk/sites/ens.dk/files/Analyser/ notat_om_kalkulationsrenten_juni_2013.pdf.

Danish Energy Agency, 2017. Basisfremskrivning 2017 (Danish energy projection 2017). URL: https://ens.dk/ sites/ens.dk/files/Forsyning/bf2017_hovedpublikation_final_12_mar.pdf.

Danish Energy Association, 2013. Endelig: Forhøjet støtte til biogas godkendt af EU (Eu approval of Danish Biogas support). URL: https://www.danskenergi.dk/Aktuelt/Arkiv/2013/November/13_11_27D.aspx.

Danish Energy Regulatory Authority, 1999. Blaabjerg biogas klage over afregningsforhold (blaabjerg biogas complaint about biogas pricing).

Danish Energy Regulatory Authority, 2017. Prisstatistik (Price Statistics). URL: http://energitilsynet.dk/ varme/statistik/prisstatistik/. accessed May 29, 2017.

Danish Government, 2012. Energiaftalen 2012 (Energy agreement 2012).

Danish Ministry of Energy, Utilities and Climate, 2016. Aftale om afskaffelse af PSO-afgiften (Agreement on abrogation of the PSO levy). URL: http://efkm.dk/media/7912/elementer-i-aftale-om-pso.pdf.

"EA Energianalyse", 2014. Anvendelse af biogas til el- og varmeproduktion. URL: http://www.ens.dk/sites/ens.dk/ files / undergrund - forsyning/vedvarende-energi / bioenergi / biogas - taskforce / rapporter_taskforce / anvendelse_af_biogas_til_el_og_varme_2.pdf.

Environmental Protection Agency, 1985. Orientering fra Miljøstyrelsen (Information from Environmental Protection Agency). URL: http://www2.mst.dk/Udgiv/publikationer/1985/87-503-5658-5/pdf/87-503-5658-5.pdf.

EuroObserv'ER, 2014. Biogas Barometer. URL: https://www.eurobserv-er.org/pdf/biogas-barometer-2014-en/. European Commision, 2013. State aid SA.35485 2012/N - Denmark Aid for all forms of biogas use.

Evald, A., Hu, G., Hansen, M.T., 2013. Technology data for advanced bioenergy fuels. Technical Report. Danish Energy Agency.

Fellner, W., 1947. Prices and Wages Under Bilateral Monopoly. The Quarterly Journal of Economics 61, 503. URL: https://academic.oup.com/qje/article-lookup/doi/10.2307/1885048, doi:10.2307/1885048.

Frisk, M., Göthe-Lundgren, M., Jörnsten, K., Rönnqvist, M., 2010. Cost allocation in collaborative forest transportation. European Journal of Operational Research 205, 448-458. URL: http://linkinghub.elsevier.com/ retrieve/pii/S0377221710000238, doi:10.1016/j.ejor.2010.01.015.

Giannoccaro, G., de Gennaro, B.C., De Meo, E., Prosperi, M., 2017. Assessing farmers' willingness to supply biomass as energy feedstock: Cereal straw in Apulia (Italy). Energy Economics 61, 179-185. URL: http: //linkinghub.elsevier.com/retrieve/pii/S0140988316303309, doi:10.1016/j.eneco.2016.11.009.

Gibbons, R., 1992. A primer in game theory. Financial Times Prentice Hall.

Harder, B., 2016. We are in the middle of the highest growth of biogas (in Danish: Vi er midt i biogassens største vækstår).

Hougaard, J.L., 2009. An Introduction to Allocation Rules. Springer Science+Business Media New York. doi:10.1007/ 978-3-642-01828-2.

Hubert, F., Ikonnikova, S., 2011. INVESTMENT OPTIONS AND BARGAINING POWER: THE EURASIAN SUPPLY CHAIN FOR NATURAL GAS. The Journal of Industrial Economics 59, 85-116. URL: http:// doi.wiley.com/10.1111/j.1467-6451.2011.00447.x, doi:10.1111/j.1467-6451.2011.00447.x. 
Jensen, I.G., Münster, M., Pisinger, D., 2017. Optimizing the Supply Chain of a Biogas Plant from Farmers to Energy Consumers Including Mass and Energy Losses. European Journal of Operational Research In Press, 1-33. Jørgensen, P.J., 2013. Praktisk anvendelse af dybstrøelse som substrat på biogasanlæg - kommende som eksisterende (Practical use of deep litter as substrate on biogas plants - future as well as existing). Technical Report. Planenergi.

Lantz, M., Svensson, M., Björnsson, L., Börjesson, P., 2007. The prospects for an expansion of biogas systems in Sweden-Incentives, barriers and potentials. Energy Policy 35, 1830-1843. URL: http://linkinghub.elsevier.com/ retrieve/pii/S0301421506002564.

Lemaire, J., 1984. An Application of Game Theory: Cost Allocation. ASTIN Bulletin 14, 61-81. URL: https: // www.cambridge.org/core/product/identifier/S0515036100004815/type/journal_article, doi:10.1017 / S0515036100004815.

Lemvig Biogas Plant, 2017. Lemvig biogas, payment for manure. URL: http://www.lemvigbiogas.com/gylle.htm. accessed May 29, 2017.

Lozano, S., Moreno, P., Adenso-Díaz, B., Algaba, E., 2013. Cooperative game theory approach to allocating benefits of horizontal cooperation. European Journal of Operational Research 229, 444-452. URL: http://dx.doi.org/ 10.1016/j.ejor.2013.02.034, doi:10.1016/j.ejor.2013.02.034.

Lyng, K.A., Skovsgaard, L., Jacobsen, H.K., Hanssen, O.J., 2018. The implications of environmental policies on biogas value chains - a case study comparison between Norway and Denmark. Submitted , 1-32.

Maabjerg Energy Center, 2017. Personal communication.

Machlup, F., Taber, M., 1960. Bilateral Monopoly, Successive Monopoly, and Vertical Integration. Economica 27, 101. URL: http://www.jstor.org/stable/10.2307/2550895?origin=crossref, doi:10.2307/2550895.

Madsen Bioenergi, 2017. Homepage of Madsen Bioenergi. URL: http://www.madsenbioenergi.dk/profil/profil2.html. accessed May 29, 2017.

Massol, O., Tchung-Ming, S., 2010. Cooperation among liquefied natural gas suppliers: Is rationalization the sole objective? Energy Economics 32, 933-947. URL: http://linkinghub.elsevier.com/retrieve/pii/ S0140988310000320, doi:10.1016/j.eneco.2010.02.008.

McCain, R.A., 2008. Cooperative games and cooperative organizations. Journal of Socio-Economics 37, $2155-2167$. doi:10.1016/j.socec.2008.02.010.

Megiddo, N., 1978. Computational Complexity of the Game Theory Approach to Cost Allocation for a Tree. Mathematics of Operations Research 3. URL: http://findit.dtu.dk/en/catalog/2293115717, doi:10.2307/ 3689489 .

Myerson, R.B., Satterthwaite, M.A., 1983. Efficient mechanisms for bilateral trading. Journal of Economic Theory 29, 265-281. URL: http://linkinghub.elsevier.com/retrieve/pii/0022053183900480, doi:10.1016/00220531 (83) 90048-0.

Nagarajan, M., Sošić, G., 2008. Game-theoretic analysis of cooperation among supply chain agents: Review and extensions. European Journal of Operational Research 187, 719-745. URL: http://www.sciencedirect.com/ science/article/pii/S0377221706007806, doi:10.1016/j.ejor.2006.05.045.

Nash, J.F., 1953. Two-Person Cooperative Games Author. Econometrica 21, 128-140.

P. Cachon, G., Netessine, S., 2004. GAME THEORY IN SUPPLY CHAIN ANALYSIS, in: Smichi-Levi, D., Wu, S.D., Shen, Z. (Eds.), Handbook of Quantitative Supply Chain Analysis: Modeling in the e-Business Era. Kluwer Academic Publishers, Boston, Massachusetts, U.S.A.. chapter 2, pp. 13-66. URL: http://findit.dtu.dk/en/ catalog/228487918, doi:10.1.1.117.6960.

Pizarro, A.R., 2014. Optimization of Biogas Use - A Modeling Assessment. Master's thesis. Technical University of Denmark.

Pool, N., 2018. Yearly day-ahead prices. URL: https://www.nordpoolgroup.com/Market-data1/Dayahead.

Radhakrishnan, S., Srinidhi, B., 2005. Sharing demand information in a value chain: Implications for pricing and profitability. Review of Quantitative Finance and Accounting 24, 23-45. doi:10.1007/s11156-005-5325-6. 
Schmeidler, D., 1969. The Nucleolus of a Characteristic Function Game. SIAM Journal on Applied Mathematics 17, 1163-1170. URL: http://epubs.siam.org/doi/10.1137/0117107, doi:10.1137/0117107.

Skovsgaard, L., Jacobsen, H.K., 2017. Economies of scale in biogas production and the significance of flexible regulation. Energy Policy 101, 77-89. URL: http://linkinghub.elsevier.com/retrieve/pii/S0301421516306176, doi:10.1016/j.enpol.2016.11.021.

Swami, S., Shah, J., 2011. Channel Coordination in Green Supply Chain Management: The Case of Package Size and Shelf-Space Allocation. Technology Operation Management 2, 50-59. doi:10.1007/s13727-012-0005-y.

Tijs, S.H., 1986. Game Theory and Cost Allocation Problems. Management Science 32. URL: http://findit.dtu.dk/ en/catalog/2295677657, doi:10.2307/2631665.

Truett, D.B., Truett, L.J., 1993. Joint Profit Maximization, Negotiation, and the Determinacy of Price in Bilateral Monopoly. The Journal of Economic Education 24, 260. URL: http://www.jstor.org/stable/1183126?origin= crossref, doi:10.2307/1183126.

Vinderup Varmeværk, 2014. Brancheforeningen for Decentral Kraftvarme (Industry organistion for decentral heat and power), presentation. URL: http://brancheforeningenkraftvarme.dk/wp-content/uploads/2011/11/ Vinderup-Varmev\%C3\%A6rk.pdf.

Von Neumann, J., Morgenstern, O., 1944. Theory of games and economic behavior. 3rd ed., Princeton University Press.

Wittrup, S., 2010. Fredericias spildevand giver biogas til gasnettet (Fredericia's waste water upgrades biogas for the grid). Ingeniøren URL: https://ing.dk/artikel/fredericias-spildevand-giver-biogas-til-gasnettet105731. 


\section{Appendix A. Regulation}

\section{Appendix A.1. Regulation related to inputs}

The primary input for biogas production must be waste in order to achieve support for biogas in Denmark. Waste can be waste water, manure, or e.g. other agricultural waste products such as waste products from dairy production or from slaughterhouses. While some of these waste products give a high biogas yield, other inputs such as manure will only give a low yield, and as some waste products are limited biogas plants have experimented with energy crops in a mix of manure. However, in order to keep a sustainable biogas production authorities have set restrictions on the level of energy crops (e.g. maize and sugar beet) which can be added in the biogas production. By 2018 this limit will be on a maximum of 12\% energy crops that can be added (Danish Energy Agency, 2012a).

Agricultural output is dependent on the amount of nutrients in the soil, and in conventional farming it is common to add a proper amount of fertilisers to the soil. These fertilisers would typically be a combination of manure and mineral fertilisers, however not all the added nutrients are used by the crops and are instead washed out into the ground water. In 1985, with the first Danish waste water action plan, it was decided to set restrictions on the amount of manure and mineral fertilisers that could be used on Danish soils (Environmental Protection Agency, 1985).

A property of digestate (de-gasified manure) is, that nutrients become more usable for the crops, which decreases the need for extra mineral fertilisers in order to achieve the same yield. With the current regulation farmers have been allowed to fertilise the soil in the same way with digestate as with untreated manure. This means that the crops are more fertilised with digestate than with untreated manure. Besides a potential profit from the biogas plant, the primary gain for a participating livestock farmer is an improved fertiliser.

\section{Appendix A.2. Regulation related to output}

Biogas support is given to the energy producer from the value chain. Until 2012, the Danish regulation followed some of the same principles as used elsewhere in Europe, where support was given to the produced electricity (EuroObserv'ER, 2014; Lantz et al., 2007; Brudermann et al., 2015). Since the Energy reform in 2012 (Danish Government, 2012), regulation have changed so that biogas upgraded to biomethane and sold on the gas market (through the gas grid) is put on the same regulatory footing as biogas used locally for heat and power production.

The support tariffs for 2016 can be seen in table A.1. The support will last until 2023, however, a part of the support will be phased out from 2016 to 2020 and another part of the support depends negatively on the natural gas price, and thereby reduce the risk of price variations for natural gas.

\section{Appendix A.3. Regulation for methanation}

As methanation is a new technology, it has not been implemented in the current support scheme, but following the fundamental principles of the support structure where production of renewable 


\begin{tabular}{l|c}
\hline Regulation type and description & value \\
\hline \hline Feed-in tariff on electricity based on Biogas & 164.9 Euro/MWh \\
Feed-in premium for heat-only based on Biogas & 55.8 Euro/MWh \\
Feed-in premium for Biomethane from biogas & 59.2 Euro/MWh \\
Fuel tax on biogas for heat & 0 Euro/MWh \\
Fuel tax on natural gas for heat & 34.3 Euro/MWh \\
\hline
\end{tabular}

Table A.1: Support and tax for upgrading and biogas-based CHP, in 2016-prices

energy is supported and not energy conversion (according to personal communication with Bodil Harder, Danish Energy Agency), we assume that the extra biomethane gained from electrolysis will not gain any support. The support and taxes for methanation are shown in table A.2.

\begin{tabular}{l|c}
\hline Regulation type and description & value \\
\hline \hline Feed-in premium for Biomethane from biogas & 59.2 Euro/MWh \\
Feed-in premium for Biomethane from electrolysis & 0 Euro/MWh \\
Fuel tax on electricity for heat based on electrolysis & 22.9 Euro/MWh \\
Tax and transport tariffs on electricity for electrolysis & 42.8 Euro/MWh \\
\hline
\end{tabular}

Table A.2: Support and taxes for methanation, in 2016-prices

Electricity is taxed even more than fossil fuels when electricity is used by private households and for heat production. This also counts for surplus heat. The tax is considerably lower, when electricity is used for industrial production, however any surplus heat from this production used for heating will then be taxed heavily afterwards, this in effect means, that a potential income from the heat generated through electrolysis is close to zero, when the tax is deducted.

A part of the electricity tax is the PSO (public service obligation), which basically is a way to make electricity consumers pay for the development of renewable electricity. The PSO fee is high and even though it is reduced a bit for large consumers it increases total electricity costs significantly. The PSO is phased out from 2017 to 2022 (Danish Ministry of Energy, Utilities and Climate, 2016), which will reduce the electricity cost significantly for industrial production such as methanation. 


\section{Appendix B. Mathematical models}

\section{Appendix B.1. Plant level model}

\section{Parameters}

$A M_{i, n^{\prime}}$ Accumulated amount of biomass for biomass type $i$ in breakpoint $n^{\prime}$

$A_{j}$ Area of circle $j$

$T$ Hours on the input side

$T$ Number of weeks in a year

$\Delta A_{j}$ Average area of circle $j$ and circle $j-1$

$\Delta d_{i, n^{\prime}}\left(\Delta d_{n^{\prime}}^{d i g}\right)$ Average transportation distance for biomass $i$ (digestate) in breakpoint $n$

$\Delta r_{j}$ Average distance from center to the biomasses in circle $j$

$\Gamma^{D M}$ Allowed dry matter content in the mix

$\eta^{E C}$ Percentage energy crops allowed in input mix

$\eta^{\text {available }}$ Amount not flared

$\eta^{\text {plant }}$ Mass after biogas plant $\%$

$\eta_{i, p^{\prime}, p} / \bar{\eta}_{p^{\prime}, p}$ Mass left after process $p$ coming from process $p^{\prime}$

$\gamma_{i}^{D M}$ Dry matter content of input $i$

$\gamma$ Percentage of mass of supplied manure that can be returned as digestate

$\bar{\eta}_{i}$ Initial biogas yield of biomass $i$

$\bar{\rho}_{p, t}$ Price of end product $p$ in time $t$

$\bar{c}_{p, p^{\prime}}^{t a x}$ Tax applied on amount flowing from process $p$ to process $p^{\prime}$

$\rho^{d i g}$ Price of digestate

$\rho_{p}^{\text {support }}$ Support process $p$

$a m_{i, m}\left(a m_{m}^{d i g}\right)$ Amount of biomass (digestate) trans-

ported on segment $m$

$a m_{i, n^{\prime}}\left(a m_{n^{\prime}}^{d i g}\right)$ Amount of biomass (digestate) in the annulus between $n^{\prime}$ and $n^{\prime}-1$

$b_{n}^{\text {plant }}$ Max. capacity of plant in breakpoint $n$

$b_{i, t}$ Biomass $i$ available at time $t$
$c^{H A N D L I N G, d i g}$ Handling cost of digestate $c_{n}^{O P E X, S O S 2} / c_{n}^{C A P E X, S O S 2}$ OPEX/ CAPEX in breakpoint $n$ for the plant

$c_{i, p, t}^{O P X, v a r} / \bar{c}_{p, t}^{O P E X, v a r}$ Variable OPEX for biomass

(gas) process $p$ for input type $i$ and time $t$

$c_{i, p}^{O P E X} / c_{i, p}^{C A P E X}\left(\bar{c}_{p}^{O P E X} /\right.$

$\bar{c}_{p}^{C A P E X}$ ) OPEX/CAPEX for biomass (gas) process

$p$ for input type $i$

$c_{i, m}^{T R A N S}\left(c_{m}^{T R A N S, x d i g}\right)$ Transport cost for biomass

type $i$ (digestate not sent to the manure supplier) on each segment $m$

$c_{i}^{\text {prod }}$ Production cost of biomass type $i$

$c_{i}^{l \text { load }} / c_{i}^{\text {unload }}\left(c^{\text {load,dig }} / c^{\text {unload,dig }}\right)$ Cost of loading/unloading biomass $i$ (digestate)

$c_{i}^{\text {truck }}\left(c^{\text {truck,dig }}\right)$ Cost of using truck for biomass $i$ (digestate)

$c_{i, n^{\prime}}^{T R A N S}$ Cost of each biomass type transported to the plant in each breakpoint $n^{\prime}$

$c_{n^{\prime}}^{T R A N S, x d i g}$ Transportation cost for digestate not delivered to the manure suppliers in breakpoint $n$

$d_{p, t}$ Demand of end product in hour $t$ - only defined for heat

$f_{p}$ Fixed amount going to process $p$ from a $\mathcal{P}^{K}-$ process

$k_{i}^{\text {truck }}\left(k^{\text {truck,dig }}\right)$ Capacity of the truck used for transportation of biomass $i$ (digestate)

$r_{j}$ Radius of circle $j$

$t_{i, p}^{\min }$ Minimum process time of process $p$ for input type $i$

$t_{i}^{\text {load }} / t_{i}^{\text {unload }}\left(t^{\text {load,dig }} / t^{\text {unload,dig }}\right)$ Time used for loading/unloading biomass $i$ (digestate)

$v_{i}\left(v^{d i g}\right)$ Velocity of truck used for transportation of biomass $i$ (digestate)

To include ownership in the model, we have included a new set of constraints to run the model with in order to see this effect. We also identified two more neccessary constraints that were not in the model from Jensen et al. (2017). The changes to the model are presented first, and after this, the rest of the model is presented.

The objective function is now to maximise the sum of profit for the owners:

$$
\operatorname{Max} \sum_{o \in \mathcal{O}} \pi_{o}
$$




\section{Sets}

$\mathcal{A}\left(v^{\prime}, v\right)\left(\overline{\mathcal{A}}\left(v^{\prime}, v\right)\right)$ Arcs from vertex $v^{\prime}$ to vertex $v$ $\mathcal{A}^{-}(v) / \mathcal{A}^{+}(v)\left(\overline{\mathcal{A}}^{-}(v) / \overline{\mathcal{A}}^{+}(v)\right)$ Input (output) side arcs entering/leaving vertex $v$

$\mathcal{A}_{\text {cap }}^{-}(v)\left(\overline{\mathcal{A}}_{\text {cap }}^{-}(v)\right)$ Arcs to vertex $v$ used in capacity constraint

$\mathcal{A}_{\text {proc }}\left(v, v^{\prime \prime}\right)\left(\overline{\mathcal{A}}_{\text {proc }}\left(v, v^{\prime \prime}\right)\right)$ Process time arcs from vertex $v$ to vertex $v^{\prime \prime}$

$\mathcal{E}$ The set of possible energy content

$\mathcal{I O}(i, o)$ Owner $o$ producing biomass $i$

$\mathcal{I}^{E C}$ Subset of biomasses that are energy crops

$\mathcal{I}$ Biomass types

$\mathcal{M}$ Line segments

$\mathcal{N}$ breakpoints

$\mathcal{O P}(o, p)$ Processes $p$ owned by owner $o$

$\mathcal{O T O}\left(o, o^{\prime}\right)$ Owners $o$ delivering output to owner $o^{\prime}$

$\mathcal{O}$ Owners in the chain

$\mathcal{P}(\overline{\mathcal{P}})$ Input (output) processes

$\mathcal{P}^{F}$ Farmer processes

$\mathcal{P}^{I}\left(\overline{\mathcal{P}}^{I}\right)$ Inner processes

$\mathcal{P}^{P}\left(\overline{\mathcal{P}}^{P}\right)$ The plant process on the input (output) side

$\mathcal{P}^{S}$ Livestock farmer processes

$\mathcal{P}^{T}$ Transportation processes

$\mathcal{T} / \overline{\mathcal{T}}$ Input (output) time steps

$\mathcal{V}(\overline{\mathcal{V}})$ Input (output) vertices

$\mathcal{V}^{F}$ Vertices of farmer processes

$\mathcal{V}^{I}\left(\overline{\mathcal{V}}^{I}\right)$ Vertices of the inner processes

$\mathcal{V}^{M}$ Vertices of the manure farmer's process

$\mathcal{V}^{P}\left(\overline{\mathcal{V}}^{P}\right)$ Plant vertices on the input (output) side

$\mathcal{V}^{T}$ Vertices of the transportation processes

$\overline{\mathcal{A}}_{\text {decide }}^{+}(v)$ The set of arcs leaving vertex $v$ which defines the capacity of the process it leaves
$\overline{\mathcal{A}}_{\text {extra }}^{+}(v)$ The set of arcs with origin in vertex $v$ but not of the main type

$\overline{\mathcal{A}}_{\text {main }}^{+}(v)$ The set of arcs leaving vertex $v$ and arriving in a process that are of the main type

$\overline{\mathcal{P}}^{E}$ End processes

$\overline{\mathcal{P}}^{H}$ End process for heat

$\overline{\mathcal{P}}^{J}$ Processes on the output side with capacity specified on output

$\overline{\mathcal{P}}^{K}$ Processes where the inflow is fixed

$\overline{\mathcal{P}}^{m^{3}}$ Methanation processes

$\overline{\mathcal{V}}^{E}$ Vertices of the end processes

$\overline{\mathcal{V}}^{H}$ End vertex for heat

$\overline{\mathcal{V}}^{J}$ Vertices on the output side with capacity specified on output

$\overline{\mathcal{V}}^{K}$ Vertices where the inflow is fixed

\section{Variables}

$C_{o}$ Cost of owner $o$

$I N C_{o}$ Income of owner $o$

$\pi_{o}$ Profit of owner $o$

$k_{n}^{S O S 2}$ If the size of the plant is near breakpoint $n$

$k_{i, p} / \bar{k}_{p}$ Capacity of biomass/gas process $p$ for biomass

type $i$

$x_{p, t}^{\text {left }}$ Not sold due to lack of demand

$x \stackrel{p m a n u r e}{ }$ Digestate not sent to manure suppliers

$x^{\text {heattax }}$ Tax paid for excess heat production

$x^{\text {should }}$ Amount of digestate that should have been to manure suppliers

$x_{m}^{\text {trans }, x d i g}$ Extra digestate transported on segment $m$

$x_{n}^{S O S 2}$ Biomasses to the plant in breakpoint $n$

$x_{a} / \bar{x}_{a}$ Flow on biomass/gas arc $a$

$x_{i, m}^{\text {trans }}$ Biomass $i$ transported on segment $m$

Where $\pi_{o}$ is the profit for each owner, $o$, in the project and is given by:

$$
\pi_{o}=I N C_{o}-C_{o} \quad \forall o \in \mathcal{O}
$$

Where $I N C_{o}$ and $C_{o}$ are the income and cost for each owner in the project. The income for each owner is described by:

$$
I N C_{o}=\sum_{\substack{v=(p, t) \in \\ \mathcal{V}^{E} \cap\left(\overline{\mathcal{P}}^{E} \times \overline{\mathcal{T}}\right) \\ \mid \mathcal{O P}(o, p)}}\left(\sum_{a \in \overline{\mathcal{A}}^{-}(v)}\left(\bar{x}_{a}-x_{p, t}^{\text {left }}\right) \eta_{a}^{\text {price }} \bar{\rho}_{p, t} \eta^{\text {available }}\right.
$$




$$
+\rho_{o}^{\text {support }}+\sum_{\substack{p \in \mathcal{P}^{\text {plant }} \\ \mid \mathcal{O P}(o, p)}} x^{\neg \text { manure }} \rho^{\text {dig }} \quad \forall o \in \mathcal{O}
$$

Here line B.1a is the income from selling the energy. This is only earned if owner $o$ owns the end process as given by the set $\mathcal{O P}(o, p)$. The amount produced on the arc $a, \bar{x}_{a}$, is reduced by the amount that cannot be sold, which is only relevant for heat as the heat demand is the limiting factor. Then the result is multiplied by a price parameter, $\eta_{a}^{p r i c e}$, which reduces the price obtained. This reduction is only applied when biomethane is produced to reflect the heating value of the produced biomethane compared to that of natural gas. Last, we multiply with the price of the end product, $\bar{\rho}_{p, t}$, and an expected percentage of which the production can occur, $\eta^{\text {available }}$. Line B.1b is the amount of support received by owner $o, \rho_{o}^{\text {support }}$, and the income, $\rho^{d i g}$, from selling the digestate, which cannot be send back to the livestock farmers, $x \neg$ manure.

The cost is given by:

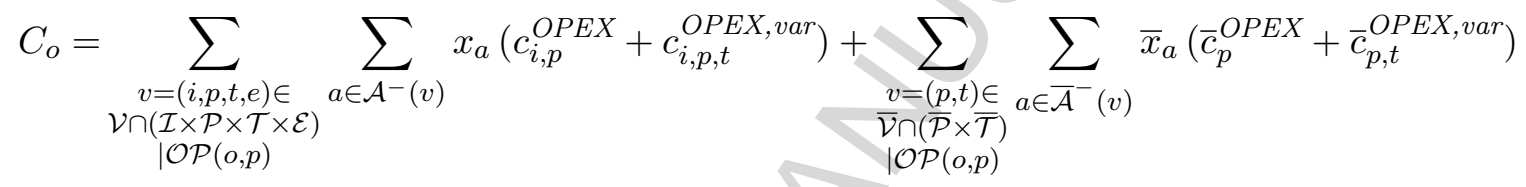

$$
\begin{aligned}
& +\sum_{i \in \mathcal{I}} \sum_{\substack{p \in \mathcal{P} \\
\mid \mathcal{O P}(o, p)}} k_{i, p} \frac{T}{t_{i, p}^{\min }} c_{i, p}^{C A P E X}+\sum_{\substack{p \in \overline{\mathcal{P}} \\
\mid \mathcal{O P}(o, p)}} k_{p} \bar{c}_{p}^{C A P E X} \\
& +\sum_{\substack{p \in \mathcal{P}^{\text {plant }} \\
\mid \mathcal{O P}(o, p)}}\left(\sum_{n \in \mathcal{N}} x_{n}^{\text {SOS2 }} c_{n}^{\text {OPEX,SOS2 }}+\sum_{n \in \mathcal{N}} k_{n}^{\text {SOS2 }} c_{n}^{\text {CAPEX,SOS2 }}\right. \\
& \left.+\sum_{m \in \mathcal{M}} x_{m}^{\text {trans,xdig }} c_{m}^{\text {TRANS,xdig }}+\sum_{v \in \mathcal{V}^{P}} \sum_{a \in \mathcal{A}^{-}(v)}\left(x_{a} \eta^{\text {plant }}-x^{\neg \text { manure }}\right) c^{\text {HANDLING, dig }}\right) \\
& +\sum_{\substack{i \in \mathcal{I} \\
\mid \mathcal{I} \mathcal{O}(i, o)}} \sum_{m \in \mathcal{M}} x_{i, m}^{\text {trans }} c_{i, m}^{\text {TRANS }}+\sum_{\substack{p \in \overline{\mathcal{P}}^{H} \\
\mid \mathcal{O P}(o, p)}} \bar{x}^{\text {heattax }}+\sum_{\substack{p \in \mathcal{P}^{S} \\
\mid \mathcal{O P}(o, p)}} x^{\text {should }} \rho^{\text {dig }}
\end{aligned}
$$

Line B.2a and B.2b are the OPEX and CAPEX of each process and is added to the cost of the owner if he owns the process as defined by the set $\mathcal{O P}(o, p)$. Line B.2c-B.2d is the OPEX and CAPEX of the plant and the transportation and handling costs of digestate. Line B.2e contains three elements. First, the transportation cost of all biomasses, which must be paid by the producer of the biomass as defined by the set $\mathcal{I O}(i, o)$. Second, the tax on excess heat delivery to the district heating network is added for the owner of the heat process. This is only relevant in the case of methanation where heat is generated as excess heat. In the model from Jensen et al. (2017), heat tax was not included. The primary reason for livestock farmers to send their manure to a biogas plant is the gains of having their manure treated and thereby a better fertiliser. If the livestock 
farmers do not receive the digestate, it represents a loss in the value chain corresponding to the digestate value, $\rho^{d i g}$. This cost is added as the final element in line B.2e.

The livestock farmers may take up to a certain percentage of the digestate, $\gamma$. The amount that is not sent back to the livestock farmer but should have been, according to the amount he is willing to take, can be calculated as:

$$
x^{\text {should }} \geq \sum_{v \in \mathcal{V}^{M}} \sum_{a \in \mathcal{A}^{+}(v)} x_{a} \gamma-\left(\sum_{\substack{v=(i, p, t, e) \in \\ \mathcal{V}^{P} \cap\left(\mathcal{P}^{P} \times \mathcal{T} \times \mathcal{E}\right)}} \sum_{a \in \mathcal{A}^{-}(v)} x_{a} \eta^{\text {plant }}-x^{\neg \text { manure }}\right)
$$

Where the first term on the right hand side represents the amount the farmer is willing to take, and the second term is the amount of available digestate minus the amount of digestate sent elsewhere.

The heat tax is the amount of heat generated and delivered to the heat demand, $p^{\prime} \in \overline{\mathcal{P}}^{H}$, from the methanation process $p \in \overline{\mathcal{P}}^{m^{3}}$, i.e. excluding the heat produced which cannot be sent to the demand, $x_{p^{\prime}, t}^{\text {left }}$. The total heat tax is calculated by the following equation:

$$
x^{\text {heattax }} \geq c_{p, p^{\prime}}^{\text {tax }}\left(\left(\sum_{v=(p, t) \overline{\mathcal{V}} \cap\left(\overline{\mathcal{P}}^{m^{3}} \times \mathcal{T}\right)} \sum_{a \in \overline{\mathcal{A}}^{+}(v)} \bar{x}_{a}\right)-\sum_{t \in \overline{\mathcal{T}}} x_{p^{\prime}, t}^{l e f t}\right) \quad \forall p \in \overline{\mathcal{P}}^{m^{3}}, p^{\prime} \in \overline{\mathcal{P}}^{H}
$$

In the model from Jensen et al. (2017), the amount of dry matter allowed in the total mix was not modelled. However, this is necessary to consider the problems obtained by the biogas plants as the dry matter content of inputs differs significantly and there is a limit on the total dry matter content of the mix. Therefore, we add another constraint that sets a limit on the dry matter content of the input mix by using the allowed dry matter content of the input mix, $\Gamma^{D M}$, and the dry matter content of each input, $\gamma_{i}^{D M}$. The constraint is given by:

$$
\sum_{\substack{v=(i, p, t, e) \in \\ \mathcal{V}^{P} \cap\left(\mathcal{I} \times \mathcal{P}^{P} \times \mathcal{E}\right)}} \sum_{a \in \mathcal{A}-(v)} \gamma_{i}^{D M} x_{a} \leq \Gamma^{D M} \sum_{\substack{v=(i, p, t, e) \in \mathcal{V}^{P} \\ \cap\left(\mathcal{I} \times \mathcal{P}^{P} \times \mathcal{E}\right)}} \sum_{a \in \mathcal{A}^{-}(v)} x_{a} \quad \forall t \in \mathcal{T}
$$

The remaining constraints are the same as in Jensen et al. (2017), and is briefly explained below.

Ensuring that the flow through the chain is remained, is accounted for by the flow conservation constraints:

$$
\begin{array}{ll}
\sum_{\substack{v^{\prime}=\left(i^{\prime}, p^{\prime}, t^{\prime}, e^{\prime}\right) \in \\
\mathcal{V} \cap(\mathcal{I} \times \mathcal{P} \times \mathcal{T} \times \mathcal{E})}} \sum_{a \in \mathcal{A}\left(v^{\prime}, v\right)} x_{a} \eta_{i, p^{\prime}, p}=\sum_{a \in \mathcal{A}^{+}(v)} x_{a} & \forall v=(i, p, t, e) \in \mathcal{V}^{I} \cap\left(\mathcal{I} \times \mathcal{P}^{I} \times \mathcal{T} \times \mathcal{E}\right) \\
\sum_{v^{\prime}=\left(p^{\prime}, t^{\prime}\right) \in} \sum_{a \in \mathcal{\mathcal { A }}\left(v^{\prime}, v\right)} \bar{x}_{a} \bar{\eta}_{p^{\prime}, p}=\sum_{a \in \overline{\mathcal{A}}^{+}(v)} \bar{x}_{a} & \forall v=(p, t) \in \overline{\mathcal{V}}^{I} \cap\left(\overline{\mathcal{P}}^{I} \times \overline{\mathcal{T}}\right)
\end{array}
$$


Minimum process time for each process is ensured through:

$$
\begin{aligned}
& \sum_{\substack{v^{\prime}=\left(i, p^{\prime}, t^{\prime}, e^{\prime}\right) \in \\
\mathcal{V} \cap(\mathcal{P} \times \mathcal{T} \times \mathcal{E}) \mid p \neq p^{\prime}}} \sum_{a \in \mathcal{A}\left(v^{\prime}, v\right)} x_{a} \eta_{i, p^{\prime}, p} \leq \sum_{\substack{v^{\prime \prime}=\left(i, p^{\prime \prime}, t^{\prime \prime}, e^{\prime \prime}\right) \in \in \\
\mathcal{V} \cap(\mathcal{P} \times \mathcal{T} \times \mathcal{E}) \mid p \neq p^{\prime \prime}}} \sum_{a \in \mathcal{A}_{p r o c}\left(v, v^{\prime \prime}\right)} \frac{x_{a}}{\left(\eta_{i, p, p}\right)^{t^{\prime \prime}-t}} \\
& \forall v=(i, p, t, e) \in \mathcal{V}^{I} \cap\left(\mathcal{I} \times \mathcal{P}^{I} \times \mathcal{T} \times \mathcal{E}\right) \\
& \sum_{\substack{v^{\prime}=\left(p^{\prime}, t^{\prime}\right) \in \\
\mathcal{V} \cap(\overline{\mathcal{P}} \times \overline{\mathcal{T}}) \mid p \neq p^{\prime}}} \sum_{a \in \overline{\mathcal{A}}\left(v^{\prime}, v\right)} \bar{x}_{a} \bar{\eta}_{p^{\prime}, p} \leq \sum_{\substack{v^{\prime \prime}=\left(p^{\prime \prime}, t^{\prime \prime}\right) \in \\
\mathcal{\mathcal { V }} \cap(\overline{\mathcal{P}} \times \overline{\mathcal{T}}) \mid p \neq p^{\prime \prime}}} \sum_{a \in \overline{\mathcal{A}}_{\text {proc }}\left(v, v^{\prime \prime}\right)} \frac{\bar{x}_{a}}{\left(\bar{\eta}_{p p}\right)^{t^{\prime \prime}-t}} \quad \forall v=(p, t) \in \overline{\mathcal{V}}^{I} \cap\left(\overline{\mathcal{P}}^{I} \times \overline{\mathcal{T}}\right)
\end{aligned}
$$

The capacity of the processes are not to be exceeded. This is ensured by the following capacity constraints:

$$
\begin{aligned}
& \sum_{v=(i, p, t, e) \in \mathcal{V} \cap \mathcal{E}} \sum_{a \in \mathcal{A}^{-}(v)} x_{a}+\sum_{v=(i, p, t, e) \in \mathcal{V} \cap \mathcal{E}} \sum_{a \in \mathcal{A}_{c a p}^{-}(v)} x_{a} \leq k_{i, p} \quad \forall(i, p, t) \in \mathcal{I} \times \mathcal{P} \times \mathcal{T} \\
& \sum_{v=(p, t) \in \overline{\mathcal{V}}} \sum_{a \in \overline{\mathcal{A}}^{-}(v)} \bar{x}_{a}+\sum_{v=(p, t) \in \overline{\mathcal{V}}_{a \in \overline{\mathcal{A}}_{c a p}^{-}(v)}} \bar{x}_{a} \leq \bar{k}_{p} \quad \forall(p, t) \in \overline{\mathcal{P}} \times \overline{\mathcal{T}}
\end{aligned}
$$

The following constraint ensures that not more than the available input is used:

$$
\sum_{a \in \mathcal{A}^{+}(v)} x_{a} \leq b_{i, t} \quad \forall v=(i, p, t, e) \in \mathcal{V}^{F} \cap\left(\mathcal{I} \times \mathcal{P}^{F} \times \mathcal{T} \times \mathcal{E}\right)
$$

The maximum percentage of energy crops allowed in the mix is handled by:

$$
\sum_{\substack{v=(i, p, t, e) \in \\ \mathcal{V}^{P} \cap\left(\mathcal{I}^{E C} \times \mathcal{P}^{P} \times \mathcal{E}\right)}} \sum_{a \in \mathcal{A}-(v)} x_{a} \leq \eta^{E C} \sum_{\substack{v=(i, p, t, e) \in \mathcal{V}^{P} \\ \cap\left(\mathcal{I} \times \mathcal{P}^{P} \times \mathcal{E}\right)}} \sum_{a \in \mathcal{A}^{-}(v)} x_{a} \quad \forall t \in \mathcal{T}
$$

The following constraints set the SOS2-variables to account for OPEX and CAPEX using stepwise linear functions for the biogas plant:

$$
\begin{aligned}
& \sum_{v \in \mathcal{V}^{P}} \sum_{a \in \mathcal{A}^{-}(v)} x_{a}=\sum_{n \in \mathcal{N}} b_{n}^{\text {plant }} x_{n}^{\text {SOS2 }} \\
& \sum_{n \in \mathcal{N}} x_{n}^{S O S 2}=1 \\
& \sum_{n \in \mathcal{N}} b_{n}^{\text {plant }} k_{n}^{S O S 2}=\sum_{i \in \mathcal{I}} \sum_{p \in \mathcal{P}^{P}} \frac{T}{t_{i, p}^{\text {min }}} k_{i, p} \\
& \sum_{n \in \mathcal{N}} k_{n}^{S O S 2}=1 \\
& b_{1}^{\text {plant }} \leq \sum_{i \in \mathcal{I}} \sum_{p \in \mathcal{P}^{P}} \frac{T}{t_{i, p}^{\text {min }}} k_{i, p} \leq b_{\text {end }}^{\text {plant }}
\end{aligned}
$$


Change of time resolution between input and output side from week to hour is done by:

$$
\sum_{\substack{v=(p, t) \in \\ \overline{\mathcal{V}}^{P} \cap \overline{\mathcal{P}}^{P}}} \sum_{a \in \overline{\mathcal{A}}^{+}(v)} \bar{x}_{a}=\sum_{\substack{v=\left(i, p,\left\lfloor\frac{t}{7 \cdot 24}\right\rfloor+1, e\right) \\ \in \overline{\mathcal{V}}^{P} \cap\left(\mathcal{I} \times \overline{\mathcal{P}}^{P} \times \mathcal{E}\right)}} \sum_{a \in \mathcal{A}^{-}(v)} \frac{x_{a} \bar{\eta}_{i} e}{7 \cdot 24} \quad \forall t \in \overline{\mathcal{T}}
$$

For processes where the capacity is determined by the output amount, the following constraint is necessary:

$$
\sum_{a \in \overline{\mathcal{A}}_{\text {decide }}^{+}(v)} \bar{x}_{a} \leq \bar{k}_{p} \quad \forall v=(p, t) \in \overline{\mathcal{V}}^{J} \cap\left(\overline{\mathcal{P}}^{J} \times \overline{\mathcal{T}}\right)
$$

For the methanation and the CHP processes, a fixed range of the two outputs are ensured by:

$$
\bar{x}_{a}=f_{p} \sum_{a^{\prime} \in \overline{\mathcal{A}}_{\text {extra }}^{+}(v)} \bar{x}_{a^{\prime}} \quad \forall v=(p, t) \in \overline{\mathcal{V}}^{K} \cap\left(\overline{\mathcal{P}}^{K} \times \mathcal{T}\right), a \in \overline{\mathcal{A}}_{\text {main }}^{+}(v)
$$

If the demand of heat is lower than the produced demand, the excess cannot be sold. This is ensured by the following demand constraint:

$$
\sum_{a \in \overline{\mathcal{A}}(v)} \bar{x}_{a} \leq d_{p, t}+x_{p, t}^{\text {left }} \quad \forall v=(p, t) \in \overline{\mathcal{V}}^{H} \cap\left(\overline{\mathcal{P}}^{H} \times \overline{\mathcal{T}}\right)
$$

The transportation constraints related to input substrates are:

$$
\begin{array}{ll}
\sum_{m \in \mathcal{M}} x_{i, m}^{\text {trans }}=\sum_{\substack{v=(i, p, t, e) \in \\
\mathcal{V}^{T} \cap\left(\mathcal{P}^{T} \times \mathcal{T} \times \mathcal{E}\right)}} \sum_{a \in \mathcal{A}^{+}(v)} x_{a} \quad & \forall i \in \mathcal{I} \\
x_{i, m}^{\text {trans }} \leq a m_{i, m} & \forall i \in \mathcal{I}, m \in \mathcal{M}
\end{array}
$$

The transportation constraints related to digestate are:

$$
\begin{aligned}
& x^{\neg \text { manure }} \geq \sum_{\substack{v=(i, p, t, e) \in \\
\mathcal{V}^{P} \cap\left(\mathcal{P}^{P} \times \mathcal{T} \times \mathcal{E}\right)}} \sum_{a \in \mathcal{A}^{-}(v)} x_{a} \eta^{\text {plant }}-\sum_{v \in \mathcal{V}^{M}} \sum_{a \in \mathcal{A}^{+}(v)} x_{a} \gamma \\
& x_{m}^{\text {trans, } x d i g} \leq a m_{m}^{d i g} \quad \forall m \in \mathcal{M} \\
& \sum_{m \in \mathcal{M}} x_{m}^{\text {trans, xdig }} \leq x^{\neg \text { manure }}
\end{aligned}
$$

Finally, restrictions on the variables are given by:

$$
\begin{array}{ll}
x_{a} \geq 0 & \forall a \in \mathcal{A} \\
\bar{x}_{a} \geq 0 & \forall a \in \overline{\mathcal{A}}
\end{array}
$$



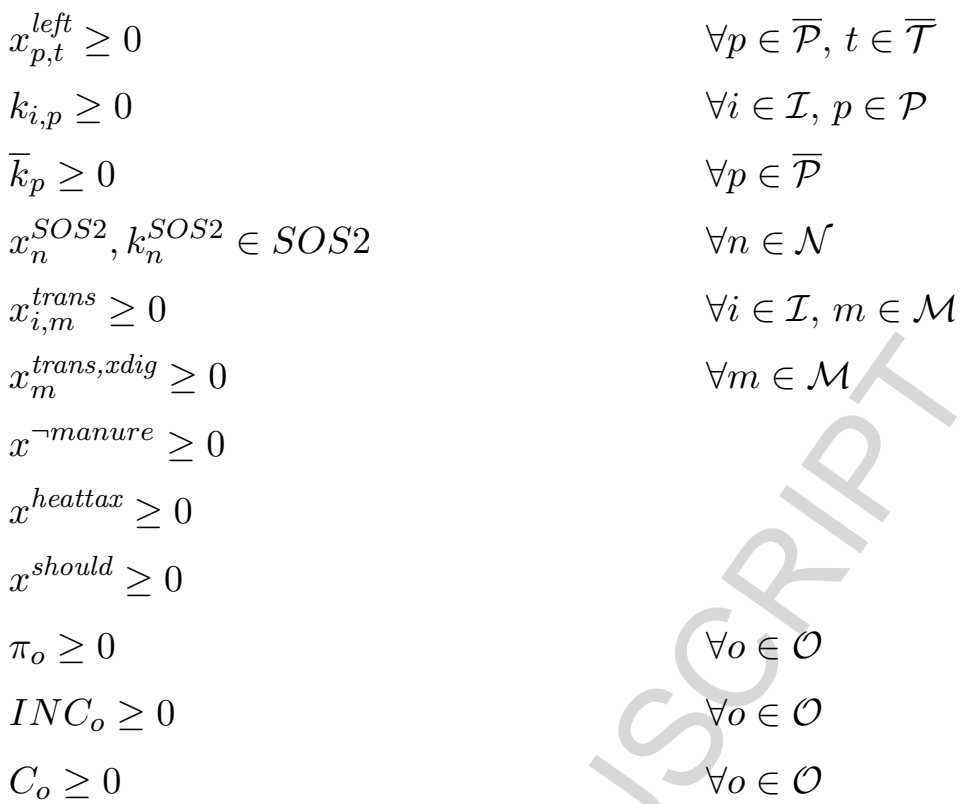

\section{Appendix B.2. Profit allocation}

The general allocation model is given below, where constraint B.5 is mechanism specific as given for each of the used allocation mechanisms.

$$
\begin{array}{llr}
\text { Max } & z=\lambda \\
\text { S.t. } & \text { Feasibility constraint } & \forall o \in \mathcal{O} \backslash \mathcal{O}^{\text {sub }} \\
& \pi_{o}^{C A}=\gamma^{\text {feas }} C_{o}^{*} & \forall o \in \mathcal{O}^{\text {sub }} \\
& \pi_{o}^{C A}=\pi_{o}^{*}-\sum_{o^{\prime} \in \mathcal{O} \mathcal{T} \mathcal{O}\left(o^{\prime}, o\right)} \rho_{\rho^{\prime}, o}^{C A}+\sum_{o^{\prime} \in \mathcal{O} \mathcal{T} \mathcal{O}\left(o, o^{\prime}\right)} \rho_{o, o^{\prime}}^{C A} & \forall o \in \mathcal{O} \\
\lambda \geq 0 & \\
& \pi_{o}^{C A} \geq 0 & \forall o \in \mathcal{O} \\
\rho_{o, o^{\prime}}^{C A} \geq 0 & \forall o \in \mathcal{O}, o^{\prime} \in \mathcal{O} \mathcal{T} \mathcal{O}\left(o, o^{\prime}\right)
\end{array}
$$

The objective function B.4 is to maximise the decision variable $\lambda$, which is specific for each of the used allocation mechanisms. Constraint B.6 sets the profit of each of the substrate owners equal to a parameter, $\gamma^{\text {feas }}$, representing the percentage of its costs from the plant level model, $C_{o}^{*}$, that should be covered. In constraint B.7, the profit for each owner using the cost allocation method, $\pi_{o}^{C A}$, is calculated as the profit obtained from the plant level model, $\pi_{o}^{*}$, minus the price paid for buying input to the process plus the price obtained from selling the output from the owner.

To apply one of the allocation mechanisms, constraint B.5 must be replaced by constraint 6 , 7 , or 8 , see section 4.3. For the full equality allocation, $\lambda$ is not used in the feasibility constraint. This means that there is no upper bound on $\lambda$ and the problem gets unbounded. To avoid this, 
we simply set $\lambda=0$.

\section{Appendix C. Data}

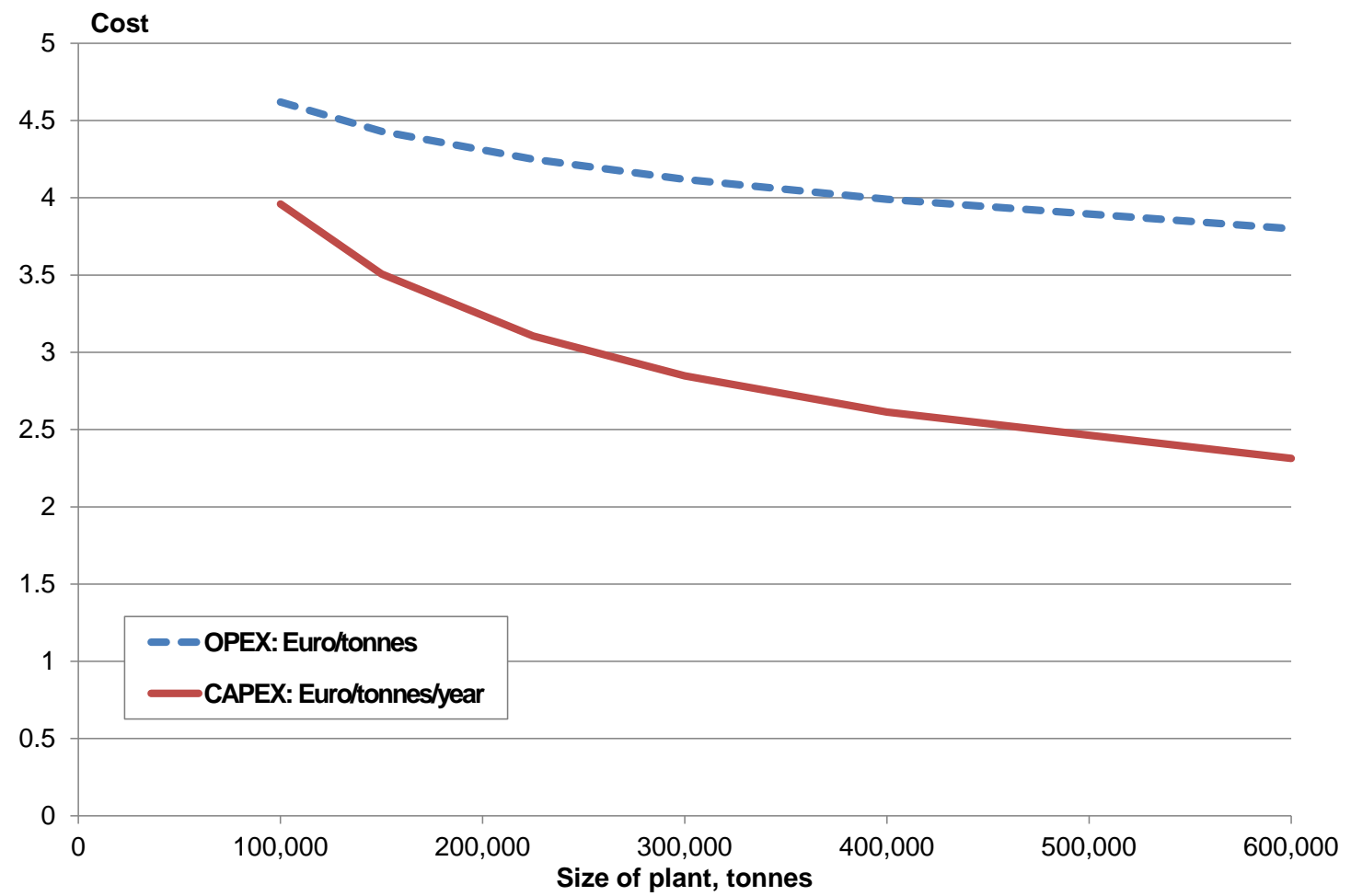

Figure C.1: OPEX and CAPEX for the biogas plant is based on a fitted trendline on the OPEX and CAPEX reported by plants applying for financial support in 2012 in Denmark through the Danish Energy Agency and model plants in the same time. To linearise it, we have used the same break points as in (Jensen et al., 2017). 


\begin{tabular}{|c|c|c|c|c|c|}
\hline \multicolumn{6}{|c|}{ Cow slurry, manure } \\
\hline Process & CAPEX & OPEX fix & OPEX var & Min. process time & Max. process time \\
\hline storage 1 & 0.12 & 0 & 0 & 1 & 4 \\
\hline storage 2 & 0.12 & 0 & 0 & 1 & 4 \\
\hline \multicolumn{6}{|c|}{ Pig slurry, manure } \\
\hline Process & CAPEX & OPEX fix & OPEX var & Min. process time & Max. process time \\
\hline storage 1 & 0.12 & 0 & 0 & 1 & 4 \\
\hline storage 2 & 0.12 & 0 & 0 & & 4 \\
\hline \multicolumn{6}{|c|}{ Deep litter, substrate } \\
\hline Process & CAPEX & OPEX fix & OPEX var & Min. process time & Max. process time \\
\hline storage 1 & 0.07 & 0 & 0 & 1 & 52 \\
\hline storage 2 & 0.07 & 0 & 0 & 1 & 52 \\
\hline pretreatment & 0.01 & 0 & 0.13 & 1 & 1 \\
\hline \multicolumn{6}{|c|}{ Maize, substrate } \\
\hline Process & CAPEX & OPEX fix & OPEX var & Min. process time & Max. process time \\
\hline ensilage & 0.00 & 0 & 0.78 & 26 & 52 \\
\hline storage & 0.30 & 0 & 0 & 1 & 17 \\
\hline \multicolumn{6}{|c|}{ Straw, substrate } \\
\hline Process & CAPEX & OPEX fix & OPEX var & Min. process time & Max. process time \\
\hline storage 1 & 1.72 & & 0 & 1 & 52 \\
\hline pretreatment & 3.61 & 0 & 10.19 & 1 & 1 \\
\hline storage 2 & 0.86 & 0 & 0 & 1 & 52 \\
\hline \multicolumn{6}{|c|}{ Sugar beet, substrate } \\
\hline Process & CAPEX & OPEX fix & OPEX var & Min. process time & Max. process time \\
\hline storage 1 & 0.26 & 0 & 1.61 & 1 & 16 \\
\hline Washer & 0.00 & 0 & 2.14 & 1 & 1 \\
\hline storage 2 & 0.26 & 0 & 1.61 & 1 & 4 \\
\hline cutter & 0.00 & 0 & 2.14 & 1 & 1 \\
\hline ensilage & 0.17 & 0 & 1.61 & 26 & 52 \\
\hline storage 3 & 0.17 & 0 & 1.61 & 1 & 4 \\
\hline
\end{tabular}

Table C.3: Data for the case study - input side. OPEX are in $€ /$ ton and all CAPEX are annualised with a rate of return of $4 \%$ and the given lifetime of the process (20 years are used when no data) and are in $€ /$ ton/year. All data are from Abildgaard (2017) except for sugar beet that are from Boldrin et al. (2016). 


\begin{tabular}{l|ccccc}
\hline \hline Biomass type & $\begin{array}{c}\text { Production cost and } \\
\text { transport to farm } € / \text { ton }\end{array}$ & $\begin{array}{c}\text { Biogas yield } \\
N m^{3} B G / \text { ton }\end{array}$ & $\begin{array}{c}\text { Dry matter } \\
\text { percentage }\end{array}$ & $\begin{array}{c}\text { Extra CAPEX } \\
€ / \text { ton/year }\end{array}$ & $\begin{array}{c}\text { Extra OPEX } \\
€ / \text { ton }\end{array}$ \\
\hline Cow slurry & 0 & 18 & $7.5 \%$ & 0 & 0 \\
Pig slurry & 0 & 17 & $5.5 \%$ & 0 & 0 \\
Deep litter & 0 & 92 & $30.0 \%$ & 1.54 & 7.51 \\
Maize & 30 & 138 & $34.0 \%$ & 0.49 & 2.41 \\
Straw & 27 & 308 & $89.0 \%$ & 4.24 & 15.42 \\
Sugar beet & 26 & 115 & $22.0 \%$ & 0.49 & 2.41 \\
\hline
\end{tabular}

Table C.4: Production costs and biogas yields of the biomass types. The biogas yield, dry matter percentage and production costs, i.e. without any storage costs etc., as well as transportation costs to the farm are given by Abildgaard (2017), where we assume a transportation distance to the farm from the field of 1.5 for maize, sugar beet, and straw. The extra CAPEX and OPEX for the feedstock are from "EA Energianalyse" (2014).

\begin{tabular}{|c|c|c|c|c|c|c|c|c|}
\hline \multirow[b]{2}{*}{ Radius } & \multicolumn{2}{|c|}{ Cow slurry } & \multicolumn{2}{|c|}{ Pig slurry } & \multicolumn{2}{|c|}{ Deep litter } & \multicolumn{2}{|c|}{ Digestate } \\
\hline & $a m_{i, n^{\prime}}$ & $c_{i, m}^{T R A N S}$ & $a m_{i, n^{\prime}}$ & $c_{i, m}^{T R A N S}$ & $a m_{i, n^{\prime}}$ & $c_{i, m}^{T R A N S}$ & $a m_{i, n^{\prime}}$ & $c_{m}^{T R A N S, d i g}$ \\
\hline 10 & 75489 & 1.20 & 138548 & 1.20 & 16298 & 3.44 & 51320 & 1.20 \\
\hline 20 & 543450 & 2.20 & 279770 & 2.20 & 56260 & 5.39 & 109521 & 2.20 \\
\hline 30 & 690273 & 3.31 & 767346 & 3.31 & 259280 & 7.56 & & \\
\hline \multirow[t]{2}{*}{40} & 819144 & 4.43 & 1032999 & 4.43 & 83638 & 9.76 & & \\
\hline & \multicolumn{2}{|c|}{ Maize } & \multicolumn{2}{|c|}{ Sugar beet } & \multicolumn{2}{|c|}{ Straw } & & \\
\hline Radius & $a m_{i, n^{\prime}}$ & $c_{i, m}^{T R A N S}$ & $a m_{i, n^{\prime}}$ & $c_{i, m}^{T R A N S}$ & $a m_{i, n^{\prime}}$ & $c_{i, m}^{T R A N S}$ & & \\
\hline 10 & 8004 & 2.55 & 1771 & 2.55 & 45363 & 6.72 & & \\
\hline 20 & 50609 & 3.44 & 6539 & 3.44 & 94926 & 8.73 & & \\
\hline 30 & 72005 & 4.43 & 8741 & 4.43 & 126407 & 10.96 & & \\
\hline 40 & 96998 & 5.44 & 9949 & 5.44 & 173821 & 13.23 & & \\
\hline 50 & 88888 & 6.46 & 14241 & 6.46 & 186082 & 15.52 & & \\
\hline 60 & 99251 & 7.47 & 11504 & 7.47 & 152538 & 17.81 & & \\
\hline 70 & 143800 & 8.49 & 13085 & 8.49 & 172816 & 20.10 & & \\
\hline 80 & 167910 & 9.52 & 17224 & 9.52 & 280636 & 22.39 & & \\
\hline
\end{tabular}

Table C.5: Data for the case study - transportation. All costs are in $€$. Further, the handling price of digestate, $c^{H A N D L I N G, d i g_{a l l}}$, is $0.40 € /$ ton. Data for the last radii is kept out for the types where it is not needed due to too large costs etc. The amount of input in each circle are data from Maabjerg Energy Center (2017), and transportation costs for all substrates as well as amount of digestate delivered in each circle is from Abildgaard (2017). 


\begin{tabular}{|c|c|c|c|c|c|}
\hline Process & CAPEX & OPEX fix & OPEX var & Min. process time & Max. process time \\
\hline gasstorage & 2.16 & 0 & 0 & 1 & 12 \\
\hline ironadsorption & 25.90 & 162.4 & 0 & 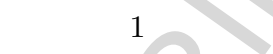 & 1 \\
\hline bioscrub & 54.74 & 32.5 & 0 & 1 & 1 \\
\hline biothrick & 44.81 & 8.1 & 0 & 1 & 1 \\
\hline waterscrub & 110.37 & 30 & 0 & & 1 \\
\hline orgphysscrub & 125.09 & 34 & 0 & 1 & 1 \\
\hline pressswingabsorp & 110.37 & 75 & 0 & 1 & 1 \\
\hline chemscrub & 110.37 & 45 & 0 & 1 & 1 \\
\hline methanation & 1471.64 & 430 & 0 & 1 & 1 \\
\hline boiler & 3840.72 & 2000 & 1.1 & 1 & 1 \\
\hline $\operatorname{scgt}$ & 38407.18 & 20000 & 4.5 & 1 & 1 \\
\hline $\operatorname{ccgt}$ & 57610.77 & 30000 & 4.5 & 1 & 1 \\
\hline gasengine & 64011.96 & 10000 & 8 & 1 & 1 \\
\hline 7 to40 & 52.61 & ( & 0 & 1 & 1 \\
\hline 1 to40 & 105.22 & & 0 & 1 & 1 \\
\hline heatstorage & 11.92 & 1.13 & 0 & 1 & 12 \\
\hline Nm3ToMWh & 0.00 & 0 & 0 & 0 & 0 \\
\hline flaring & 8093.99 & 0 & 0 & 0 & 0 \\
\hline
\end{tabular}

Table C.6: Data for the case study - output side (Danish Energy Agency, 2012c; Evald et al., 2013; Pizarro, 2014). All costs are in $€$, and all CAPEX and fixed OPEX are annualised with a rate of return of $4 \%$ and the given lifetime of the process (20 years are used in case of no data). For Boiler, Single-cycle gas turbine (SCGT), Combined-cycle gas turbine (CCGT), and Gas engine CAPEX and OPEXfix are in €/MW/year and OPEX in €/MWh. For the other technologies, CAPEX and OPEXfix are in $€ / \mathrm{Nm} 3 / \mathrm{h} /$ year and none of these has any assigned variable OPEX. We have used a higher heating value of methane of $39.8 \mathrm{MJ} / \mathrm{Nm} 3$ and a lower heating value of $35.9 \mathrm{MJ} / \mathrm{Nm} 3 \mathrm{and}$ assume the methane content of biogas to be $65 \%$, while the methane content of biomethane differs depending on the upgrading technology used. 


\section{Highlights}

- A mixed integer programming model is used to find the optimal biogas value chain

- Three allocation mechanisms are applied to determine a profit allocation sample space

- Cooperative game theory is applied to explain recent trends in the biogas industry

- The preference for upgrading can be due to strategic thinking from the biogas plant

- Poor bargaining power can explain why farmers hesitate to join biogas projects 